Article

\title{
Sustainable Industry 4.0 in Production and Operations Management: A Systematic Literature Review
}

\author{
Andreas Felsberger $1, *$ (D) and Gerald Reiner ${ }^{2}$ \\ 1 Department of Operations, Energy and Environmental Management, University of Klagenfurt, \\ 9020 Klagenfurt, Austria \\ 2 Department of Information Systems and Operations, Institute for Production Management, \\ Vienna University of Economic and Business, 1020 Vienna, Austria; gerald.reiner@wu.ac.at \\ * Correspondence: andreas.felsberger@aau.at; Tel.: +43-463-2700-4075
}

Received: 24 August 2020; Accepted: 23 September 2020; Published: 26 September 2020

\begin{abstract}
This study draws attention to the upcoming changes within sustainable value chains and manufacturing environments caused by the digital transformation. With a special focus on Industry 4.0 (I4.0), the presented study explores the scientific progress within this research field. A systematic literature review approach using a set of predefined keywords and with several exclusion criteria was adopted in order to identify the literature that is related to sustainability in I4.0 and its impact in the area of production and operations management (P\&OM). A total of 89 papers from the period 2010-2020 were identified, which were then examined along the lines of the most influential journals, key topics of the selected literature, geographical distribution, and sustainability dimensions. The analysis was executed via bibliometric and text mapping tools, namely NVivo and BibExcel. Furthermore, a focus group discussion with experts from European semiconductor manufacturing companies and researchers from several academic institutions was conducted to derive practical insights. The results of this study will contribute to the evaluation of sustainable I4.0 innovations from the past 10 years. The key issues and research gaps identified in this article will provide a reference point to encourage and guide interested researchers for future studies, thus supporting both theoretical and practical progress in this research area.
\end{abstract}

Keywords: Industry 4.0; sustainability; triple bottom line; systematic literature review; focus group discussion; production and operations management

\section{Introduction}

The trend towards an increasingly digitally transformed manufacturing environment is an emerging topic for researchers and practitioners of different fields [1,2]. The reason for focusing attention on the impact evaluation of Industry 4.0 (I4.0) technologies for sustainable production and operations management (P\&OM) is explained by the importance of developing more efficient and effective value chains and simultaneously reducing resource consumption [3]. In this paper, we examine the topic through the lens of the resource-based view (RBV) theory [4]. I4.0 is intended to contribute to the redirection of resources into the core competencies of a company in order to sustain competitive advantages [5-7]. Resources are defined as a firm's tangible and intangible assets such as skills and technological know-how, assets, capabilities, and processes or other attributes of the firm [8]. Digital technological development can be considered as a resource, but I4.0 is more than just a development in technology; it is a value-creating strategy, which enhances and sustains a firm's competitive advantage [5,9]. This is achieved by transforming existing resources and skills into core capabilities and by simultaneously introducing new ones that are rare, inimitable, and not substitutable [5]. Kagermann [10] outlined 
that I4.0 follows a fusion of the virtual and the physical world in order to ensure energy and resource efficiency, improvement, and innovation in productivity as well enhancement of the frequency of the time-to-market cycle [10].

Various European manufacturing industries have invested in an increasing number of activities to develop and explore the potential of digital technologies in order to remain competitive in an era of digital transformation. The integration of smart systems and new management approaches in the context of I4.0 becomes increasingly important due to improved value chain management [11]. Value chain management includes the management of material, information, and cash flow while considering stakeholder requirements [12].

The implementation of digital technologies may solve different issues that core business possesses such as production processes, organizational structures, and supply chain management face [13]. In contrast, the impact of I4.0 technologies, such as embedded systems and cyber-physical system architecture, on the performance of sustainable $\mathrm{P} \& \mathrm{OM}$ as well as the measurement of the impacts of adopting these technologies, exemplifies a gap in research. To reach sustainability, a balance of economic, environmental, and social performance is required, i.e., interdependencies between the three dimensions of the triple bottom line (TBL) are at the core of sustainability [14]. In order to evaluate the integration of new technologies, it is crucial to measure the effects that arise [15]. In this study, we strive for a systematic literature search regarding sustainable I4.0, in order to further develop this field of research and to uncover potential areas of research. The following research questions (RQs) aim to explore the impact of sustainable I4.0 on value chain performance within the domain of P\&OM:

- RQ1: What is the current state of research regarding the impact of I4.0 on sustainable production and operations management?

- RQ2: What is the impact of I4.0 on the economic, environmental, and social dimensions of sustainability?

This paper is structured as follows: first, the review methodology is discussed, followed by first data analysis and descriptive statistics. The third chapter describes the qualitative content analysis of the investigated papers. The results of the literature review are presented and lead into the findings of the expert focus group discussions. Finally, the results of the paper are presented and a conceptual framework of the modified technological TBL approach is provided.

\section{Theoretical Foundations}

I4.0 describes the fourth industrial revolution, which transforms the manufacturing industry based on integrating information and communication technology and intelligent, data-driven and automated decision making [16]. I4.0 refers to the decentralized and product-centric control of business processes brought about by technological advances [17]. In general, I4.0 serves as a concept regarding how future customer demands, resources and data are shared, used, organized, and recycled to make a product or deliver a service faster, cheaper, more efficiently and more sustainably $[16,18]$. The integration of I4.0 based information and communication technologies within organizations has enabled autonomous and dynamic manufacturing [19-21].

In addition, these technologies can include various innovative applications such as real-time monitoring, improved control systems or advanced process digitization e.g., novel methods for tracking and monitoring activities along the supply chain $[13,22]$. The transformation of business process control systems has significantly changed the manufacturing performance of companies [23]. In addition, these technological innovations have enabled efficient use of resources, making sustainable performance a key feature of intelligent factories [24]. Business processes will become more transparent, efficient and sustainable through a dynamic integration of man and machine along the entire value chain [25]. The latest studies by Beier et al. [26] and Galatai and Bigliardi [27] prove that I4.0 is an enabler for sustainable development. For example, de Man and Strandhagen [28] examine the effects of I4.0 on sustainable business models. Others such as Bonilla et al. [29] discuss the sustainability impact and challenges of I4.0 on environmental firm performance. A study by Ghobakhloo [30] contributes to 
exploring the sustainability literature by identifying sustainability functions (economic, environmental and social) of I4.0 and drawing contextual relationships among these I4.0 sustainability functions applying a structural modelling technique.

Digital transformation is currently a particularly important strategic success factor for many manufacturing companies, enabling the efficient handling of unpredictable factors influencing sustainable business performance and achieving decisive competitive advantages over competitors [31]. The integration of intelligent systems and the introduction of digital technologies has led to new management approaches and capabilities. The exploitation of these new potentials through digitized solutions within I4.0 has gained in importance due to the increased customer demands on the value chains [11,32]. In addition, the business environment is becoming very dynamic in terms of economic (costs, resources, productivity, product complexity), social (demanding customers, changing markets, changing organizational cultures) and environmental (energy efficiency, waste and climate change) requirements $[33,34]$. The digital transformation is changing the manufacturing landscape as companies begin to use the Internet of Things to connect manufacturing assets, big data analytics to monitor plants, and artificial intelligence to support decision-making processes. As a result, the progressive incorporation of information and communication technologies (ICT) [25] and their combination with production process technologies has made manufacturing operations more intelligent and sustainable [35].

Since its introduction, a lot of attention has been paid to the term I4.0 by academics and practitioners. Driven by both an application-pull and a technology-push [36], an embedding of fast-developed applications and new digital solutions in on-going operations as well as a rapid increase in research projects has emerged. Nowadays, European manufacturing companies try to reach uniqueness through the adaption of new intelligent technologies to enhance their existing business processes and to increase organizational learning [37]. In this study, we analyze parts of this theoretical construct in order to establish the basis for further discussions and research in this field.

\section{Research Methodology}

The research methods applied in this paper are a systematic literature review in combination with qualitative content analysis, followed by a focus group discussion with experts from the electronics component and systems domain of Europe. A systematic literature review is a transparent, objective, and bias-reducing methodology [38]. Fink [39] stated that "a literature review is a systematic, explicit and reproducible design for identifying, evaluating, and interpreting the existing body of recorded documents" [39]. Moreover, a literature review aims to summarize existing research by identifying patterns, themes, and issues within academic literature. This methodology allows scholars, scientists, and academics to identify relevant research work based on citation frequencies and pre-defined criteria [40,41]. The development of search strings is an essential part of a systematic literature review. After defining the search strings, the Business Source Premier (EBSCO) and Web of Science (WoS) meta-databases were scanned for scientific papers that fulfill the inclusion criteria. Finally, the identification of the conceptual content of the field is provided and contributed to theory development [42].

The qualitative results of the literature review suggest that expert surveys or discussions serve as a basis for the progressive knowledge research within I4.0 topics. In order to underpin our theoretical analysis with hands-on perspectives, we decided to apply the focus group discussion technique to the study results as well; in this way, we could also gain practical insights from experts of the European electronics component and systems industry (ECS), with which we would be able to expand existing theories in this research area. The objective was to amplify knowledge and to gain better access to the expectations of several industrial companies and research centers. A focus group consists of a group of individuals that are selected and established by researchers to discuss and explicate a specific topic by proposing their own experiences and know-how [43]. We attempt to evaluate the current knowledge and expectations of the industrial partners concerning the impact of I4.0 use cases and technological applications. According to Fern [44], focus groups are useful instruments for collecting information and expectations in an exploratory way. Within exploratory focus groups, it is possible to 
create, collect, identify, discover, or explain thoughts, feelings, and behaviors. As pointed out in Table 1, we evaluated and created new ideas, collected unique thoughts, and endeavored to identify needs, expectations, and issues regarding the socio-economic as well as the technical and environmental impact of I4.0 applications. From these results, it is possible to generate theoretical constructs or hypothesized relationships in order to build models, hypotheses, or theories [44]. Both methodologies come up with certain limitations. First, a systematic literature review includes individual, subjective exclusion and inclusion criteria. These criteria have to be made as transparent as possible in order to prove credibility. Only by assuring transparency, can scholars more confidently re-use the results in their own research [45]. To overcome this limitation, we illustrate the search strings as well as the filtering criteria in Tables 2 and 3 within this paper. In addition, systematic literature reviews have inherent shortcomings. For example, ensuring the heterogeneity of the observed articles, avoiding the loss of information on important results or duplication of publications [46]. Systematic literature reviews might not generate practical recommendations. Findings are often too broad, too incomparable, and too theory oriented [47]. Secondly, limitations to focus group discussion are presented. The focus group discussion technique relies on moderators to guide the group's discussion. The moderator must have a set of skills and techniques to ensure the questions are addressed comprehensively and not to encourage participants to respond to the researcher's prejudices [48]. The method must be suitable to answer the research questions related to the investigated phenomenon. A clear rationale for the choice of focus group discussion must be provided [49]. Furthermore, generalizing results, based on the group information is difficult due to limited number of participants and the representativeness of the sample [50]. Finally, participants with strong personalities may dominate the discussion, leading to "false" consensus [50-52].

As a first step, a brainstorming session was held during which focus group participants provided their thoughts and expectations. The second step was to form small groups with four participants each, in which the statements regarding the expectations and thoughts of each participant were examined and discussed. As per the focus group methodology guideline, two moderators led the discussions. In the third step, the results of the discussion were presented by the focus group members and recorded by the moderators.

Table 1. Framework for focus group research, based on Fern [44].

\begin{tabular}{ll}
\hline \multicolumn{3}{c}{ Explanatory Focus Group Research } \\
\hline Effect Applications & Theory Applications \\
\hline Creation of & \\
- New ideas & Generation of \\
- Innovations & - Theoretical constructs \\
Collection of & - Hypothesized relationships \\
- Unique thoughts & Development of \\
Identification of & - Models \\
- Needs $\quad$ Expectations & - Typotheses \\
- $\quad$ Theories \\
- Issues
\end{tabular}

\subsection{Preparation of Literature Search}

When preparing for a literature search, it is of high importance to develop a research framework and a review procedure, as illustrated in Figure 1. One must find a gap in the investigated literature and, therefore, explicit research questions (RQs) have to be created [53]. In our paper, we defined two RQs which are related to I4.0 and sustainability. The next steps are selecting the appropriate search terms, conducting the meta-search, which includes collecting articles, filtering and refining the initial results, and eliminating redundant papers, which leads to the final size of the paper sample. The final 
paper sample size allows the development of further lines of investigation such as quantitative and qualitative content analysis.

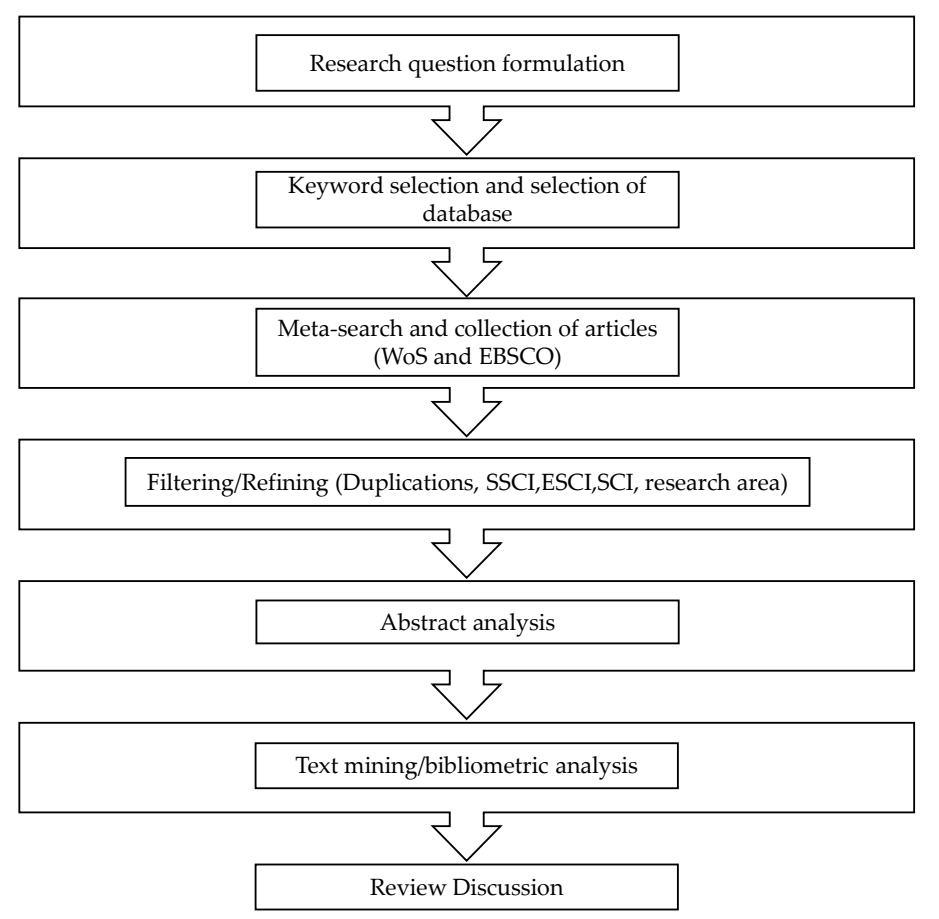

Figure 1. Procedure of a systematic literature review.

\subsection{Search for Literature}

The search strategy was developed by going through sources of relevant data. In order to cover a wide range of academic publications, Web of Science (WoS) and Elton Bryson Stephen Company (EBSCO) Academic Search Ultimate served as the main meta-databases for conducting the literature review. After defining the sources for the research data, search strings were developed (Table 2). The search strings were generated by scanning abstracts, topics, titles, and author-supplied keywords of state-ofthe-art articles within the paper sample. The combination of the two databases, WoS and EBSCO, allowed for an examination of the relevant state-of-the-art literature. In the first search, an outcome of 186 articles was generated.

Table 2. Search strings.

\begin{tabular}{ll}
\hline \multicolumn{1}{c}{ Database } & \multicolumn{1}{c}{ Search String } \\
\hline \multirow{2}{*}{ Web of Science } & $\begin{array}{l}\text { TI = (IOT OR Industry 4.0 OR I4.0 OR digitalization OR digital transformation) AND TI } \\
=\text { (Sustainability OR Triple Bottom Line OR TBL OR Sustainable OR economic impact OR } \\
\text { environmental impact OR social impact OR sustainable manufacturing OR sustainable } \\
\text { Operations OR sustainable supply chain management OR sustain*) }\end{array}$ \\
& TI((IOT OR Industry 4.0 OR I4.0 OR digitalization OR digital transformation) AND \\
EBSCO Academic & TI((Sustainability OR Triple Bottom Line OR TBL OR Sustainable OR economic impact \\
Search Ultimate & OR environmental impact OR social impact OR sustainable manufacturing OR \\
& sustainable Operations OR sustainable supply chain management OR sustain*)) \\
\hline
\end{tabular}

The study aims to provide a comprehensive overview about the state-of-the-art in scientific research. Therefore, the included material should fulfill specific evaluation requirements, including different quality and content criteria. Table 3 illustrates the quality and content criteria and the number of papers after filtering. For our evaluation, we only investigated publications in peer-reviewed journals. This was in order to ensure that only high-quality literature from academic sources was taken 
for evaluation. The initial results were filtered by excluding book chapters, books, doctoral theses, conference papers, and commercial papers. The main quality criterion was to check the ranking of the journal articles in the Science Citation Index that fulfilled this criterion. Therefore, we considered different indexes such as the Science Citation Index-Expanded (SCIE), Social Science Citation Index (SSCI), Arts \& Humanities Citation Index (AHCI), and the Emerging Sources Citation Index (ESCI), and we investigated journals that are listed in the Journal Citation Reports (JCR)-ranking list, which resulted in a total of 150 articles. Furthermore, papers that passed this initial step were refined based on the timespan being considered (2010-2020), language (only English), and selected research domains, resulting in 142 articles. The search results of the databases were also analyzed and filtered for redundant papers which were eliminated [54]. In doing so, the total number of articles (135) was reduced to 121 publications.

Finally, papers had to fulfill the content criteria in terms of I4.0 and sustainability in the domain of $\mathrm{P} \& O M$ research. The content related requirement for papers to be included in the study was the explicit focus of I4.0 on sustainability in P\&OM areas. The articles were categorized according to manufacturing, supply chain and service operations. Furthermore, only articles that clearly address I4.0 technologies influencing one or more dimensions of sustainability i.e., people, profit and planet were considered. In order to do so, we manually screened the abstracts, keywords and the conclusions of all relevant scientific articles as proposed by Jahangirian et al. [55] and Jena et al. [56]. This process of screening allowed a further reduction of the total to 89 articles in the relevant research field.

Table 3. Filtering (exclusion/inclusion) criteria and numbers of papers after filtering.

\begin{tabular}{ccc}
\hline & Evaluation Criteria & No. of Papers \\
\hline & Initial search string & 186 \\
& Limitation to only journal papers (excluding conference papers, books, book series, & 150 \\
& commercial publications, doctoral thesis etc.) including SCIE, SSCI, AHCI, ESCI & 144 \\
& Limitation to English language papers & 142 \\
& Limitation to timespan 2010-2020 & 135 \\
& Exclusion of non-relevant research areas (health sciences etc.) & 121 \\
& Exclusion of redundant papers & 89 \\
\hline
\end{tabular}

\section{Descriptive Statistics}

In the first step, the papers were investigated by means of a descriptive analysis. The following descriptive dimensions were used to classify the papers [15]:

1. How are the publications distributed across the time period?

2. In which journals are the assessed articles published?

3. Geodata analysis using https://www.gpsvisualizer.com/

4. Which dimensions of the TBL approach are addressed?

5. Initially, a review framework was developed to answer RQ1 and RQ2.

To identify potential research gaps concerning the impact of I4.0 technologies on sustainability, the scientific articles are classified in line with their focus on research. This descriptive analysis lays the foundation for assessing the current state of research and the direction of development required in the area of sustainable I4.0 environments.

\subsection{Year-Wise Publications}

The initial data statistics represent a set of the results of the descriptive analysis, including the trend of publication of the articles (Figure 2), which shows the number of papers plotted against the years in the timespan. 


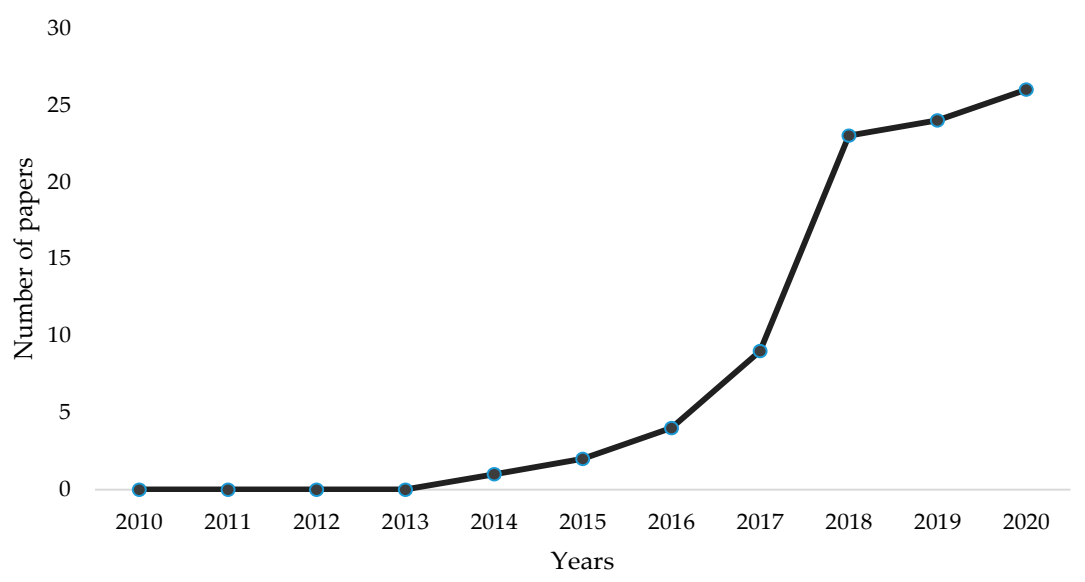

Figure 2. Publications over time.

We investigated the research period of 2010 to 2020. The rationale behind our focus on analysis of the literature over the last 10 years is the evolution of the subject area. I4.0 is a field that has been emerging since 2010 and therefore, we aimed to cover the whole spectrum of published articles considering sustainability. The scientific field of sustainability in I4.0 expanded in 2014 and has become more and more important in the last three years. In our review, we found that the first papers were not published until 2014, with the first being by Herrmann et al. [57]. The researchers conducted a review on the development and new trends in manufacturing and a comparison of factory perspectives in order to present different visions of the factory of the future paradigm by simultaneously reviewing different I4.0 technologies as main enabling factors [57]. Until 2017, the research interest in the field of I 4.0 as an enabling factor for sustainability was very low. Following a gap of two years, the field of sustainability in I4.0 experienced a rapid increase in 2018.

We observed that $67 \%$ (62) of the papers were published in journals with a focus on the field of P\&OM. The publications are widely spread across 15 journals with production, logistics, or operations management content (See Table 4).

The remaining 33\% (27) papers were published in 26 different journals with lower citation frequencies and impact factors that are subsumed under the "other" category in Figure 3. Since 2017, there has been an overall increase in the trend of publications with massive peaks in the years 2018, 2019, and 2020. The 89 papers were published in 40 different journals. Interestingly, a large number of publications was found in 2019 led by the journal named "Sustainability" (11). Our sample determines that the largest amount of papers were produced in the year 2020 (data collected until July). By setting the focus on the dimensions of sustainable development, a huge amount of current research papers are distinguishable. Most of these papers were published in different journals with different research focus areas subsumed under the "other" category. This fact allows us to recap the current situation on researching I4.0 topics. Scientific literature is produced every day but remains somewhat predictive in nature. With reference to our literature review, no highly cited papers were published concerning this content. The Journal of Cleaner Production (JCP) published eight papers during the last three years with a high concentration of topics like impacts of information systems on supply chain management practices, production network systems or big data approaches [30,58-61]. The selected publications from the International Journal of Production Research (IJPR) (five), the Journal of Manufacturing Technology Management (JMTM) (four), Process Safety \& Environmental Protection (PSEP) (four), Annals of Operations Research (AOR) (two), Production Planning \& Control (PPC) (two) and the International Journal of Operations \& Production Management (IJOPM) (one) represent frequently cited papers within this research area. The most important contributions regarding I4.0 and its impact on sustainability were made by Birkel et al. [7], de Sousa Jabbour et al. [62], Müller and Voigt [63] and Kamble, Gunasekaran et al. [64]. 


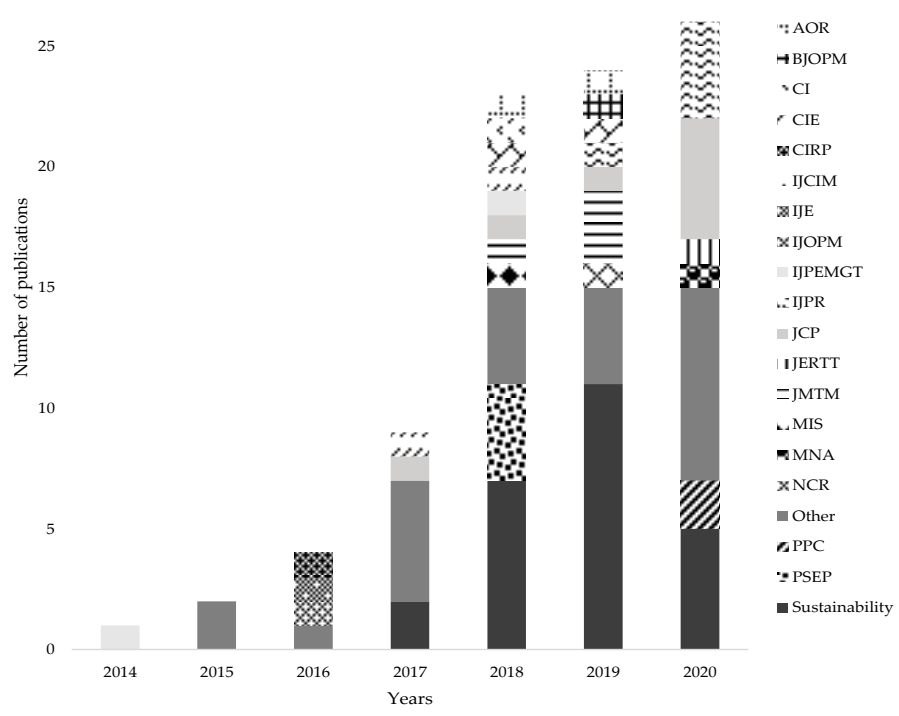

Figure 3. Number of publications per year and by journal.

\subsection{Detailed Analysis of Journal Contributions}

The journal classification was extracted using the BibExcel tool based on the Research Information Systems (RIS) file exported from WoS and Citavi 6. For our analysis, we focused on journals that published more than one paper. The journals that have published more than one article, which are composed of a total of 62 articles, and which account for $60 \%$ of the articles examined, are listed in Table 4. Sustainability, JCP, IJPR, JMTM, and PSEP have more than two publications each.

Table 4. Journals with more than one publication.

\begin{tabular}{|c|c|c|c|c|c|c|}
\hline Journal & 2014 & 2017 & 2018 & 2019 & 2020 & Total \\
\hline Annals of Operations Research & & & 1 & 1 & & 2 \\
\hline Computers \& Industrial Engineering & & & 1 & 1 & & 2 \\
\hline Energies & & 1 & 1 & & & 2 \\
\hline Entrepreneurship and Sustainability Issues & & 1 & & 1 & & 2 \\
\hline International Journal of Computer Integrated Manufacturing & & 1 & 1 & & & 2 \\
\hline $\begin{array}{c}\text { International Journal of Precision Engineering and } \\
\text { Manufacturing-Green Technology }\end{array}$ & 1 & & 1 & & & 2 \\
\hline International Journal of Production Research & & & & 1 & 4 & 5 \\
\hline Journal of Cleaner Production & & 1 & 1 & 1 & 5 & 8 \\
\hline Journal of Manufacturing Technology Management & & & 1 & 3 & & 4 \\
\hline Process Safety \& Environmental Protection & & & 4 & & & 4 \\
\hline Production Planning \& Control & & & & & 2 & 2 \\
\hline Sustainability & & 2 & 7 & 11 & 5 & 25 \\
\hline Technological Forecasting and Social Change & & & 1 & & 1 & 2 \\
\hline Total & 1 & 6 & 19 & 19 & 17 & 62 \\
\hline
\end{tabular}

\subsection{Keyword Statistics}

Using the BibExcel tool, the most common author keywords in all papers were extracted and are shown in Figure 4. Here, "Industry 4.0" (8\%) was the most frequently used keyword, followed by "sustainability" (7\%), "management" (4\%), "Internet of Things (IoT)" (4\%), and "big data" (3\%). 

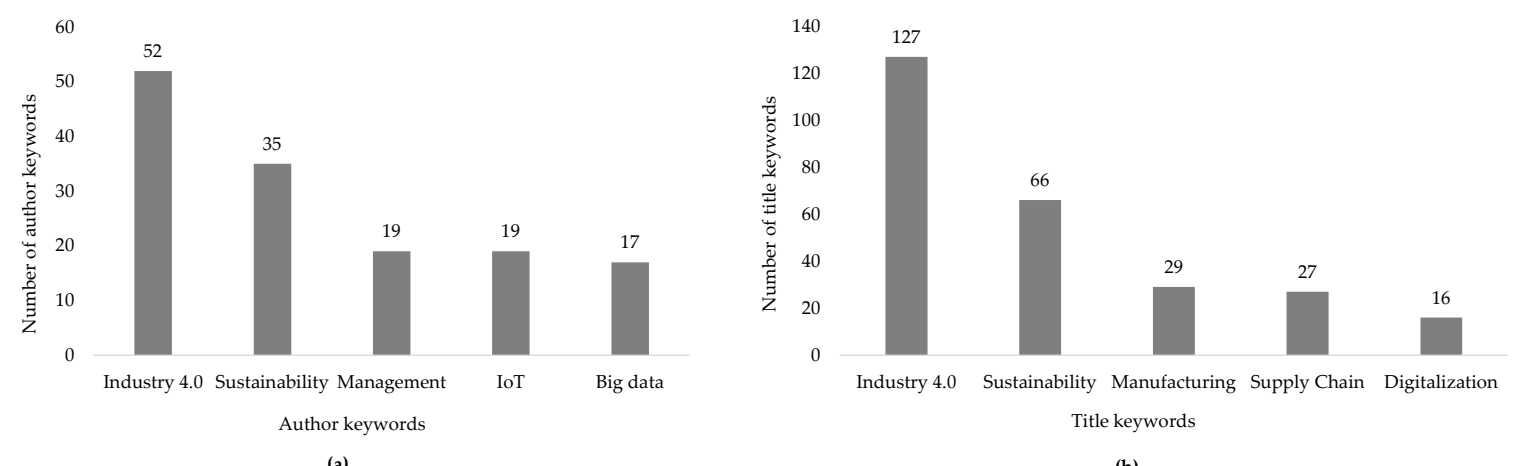

(b)

Figure 4. (a) Top five author keywords; (b) Top five title keywords.

Furthermore, Figure 4 represents the top five title keywords of the publications. "Industry 4.0" was present with $33 \%$, followed by "sustainability" (17\%), "manufacturing" (8\%), "supply chain" $(7 \%)$, and "digitalization" (4\%).

\subsection{Affiliation Statistics}

The authors' affiliations and city names were determined from the RIS data using BibExcel. To create the geographic information system (GIS) map, the tool "gpsvisualizer" was used. Please note that each author of all the papers is assigned the country that is his or her respective affiliation belongs to. Therefore, multiple assignments of one article are also possible.

In total, 212 affiliations were identified. The red spots in Figure 5 reflect the contribution of each organization. Interestingly, research focusing on I4.0 contributing to sustainability has mainly been dedicated to Europe as well as the Far East and the Southeast regions of Asia. One reason for this result could be the high EU funding for European countries that are part of the I4.0 environment, which meant that Europe's researchers had early access to I4.0 topics. For example, the European Commission's strategic research roadmap includes the coordination of continental, national, and regional I4.0 initiatives for shaping the digital transformation in Europe [65]. In order to safeguard Europe's manufacturing industry, the EU has proposed a tremendous number of short-term and mid-term actions. For example, a dedicated area of focus is the digital transformation of the European industry and service sectors. A budget of EUR 1.8 billion has been allocated for this purpose in the timespan of 2018-2020 [65]. "Made in China 2025," China's strategic I4.0 plan, is an initiative to comprehensively upgrade China's manufacturing industry and to position the country as the number one industrial power worldwide [66]. In China, R\&D spending is government-controlled, which ensures the country's rapid development and high funding for research [63].

In Figure 6, only countries with more than two contributions are presented. Germany dominates the list with 24 contributions from authors out of the selected 89 papers, followed by India (21), Italy (18), the UK (18), China (17), Spain (15), and Brazil (11). Interestingly, only five authors contributed to this research field from the USA. To strengthen a country's position in the global marketplace, some government-based initiatives have been introduced around the world. I4.0 was a strategic initiative introduced by the German government aiming at industrial production systems. This is not surprising as Germany has one of the most competitive manufacturing industries in the world [67]. The term Industry 4.0 emerged in 2011, at the Hannover fair. Since its introduction, I4.0 has been considered as one of the key issues for industrial progress in Germany and is treated as such by academic and industrial communities [16]. This is also the reason for the high proportion of research work originating from Germany. 


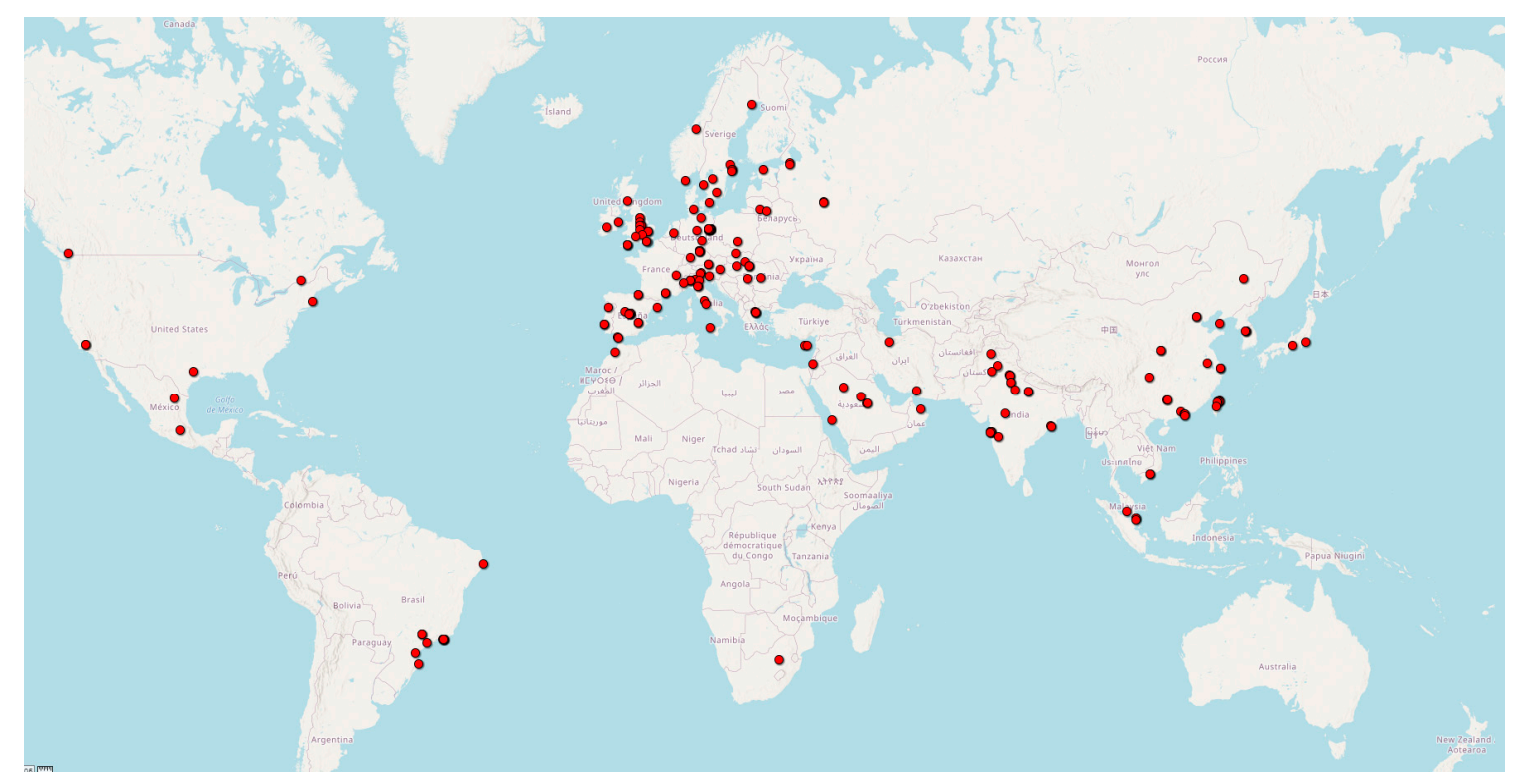

Figure 5. Geocoding results of contributing organizations.

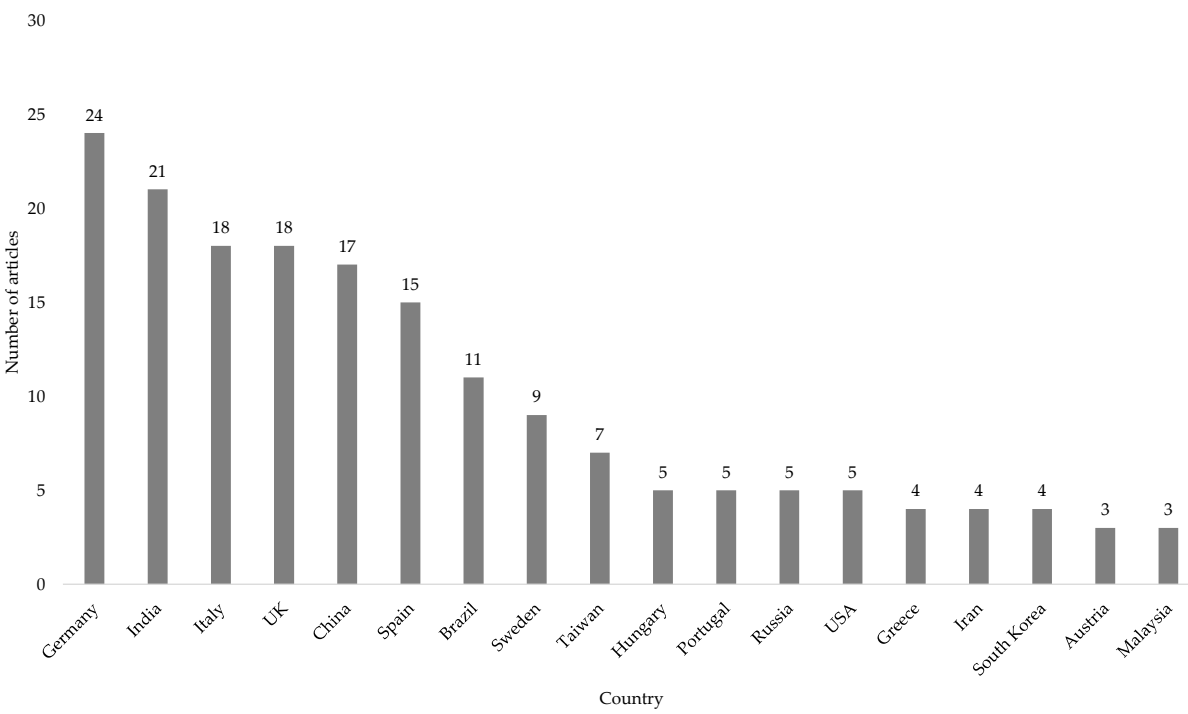

Figure 6. Number of articles by country.

\section{Qualitative Content Analysis}

\subsection{Keyword Frequency Analysis}

The application of several quality criteria enabled the first step of the selection process. We only investigated papers that conformed to our content criteria. For the qualitative content analysis, we imported the RIS file into the data analysis software NVivo 12 Plus. NVivo 12 is used for qualitative and mixedmethod research analysis [68]. In our paper, we used this software to conduct a content analysis for the selected 89 papers. Firstly, different observation categories were developed, as presented in the subsections of this chapter. Second, papers were coded by applying the text search and word frequency queries in NVivo.

I 4.0 covers a broad range of different topics within the P\&OM domain. In order to identify the most common research topics within the field, we adopted a keyword frequency query. First, we used NVivo to run a keyword search highlighting the most frequent keywords mentioned in the sample and compiled the words into a word cloud according to their frequencies (Figure 7). 


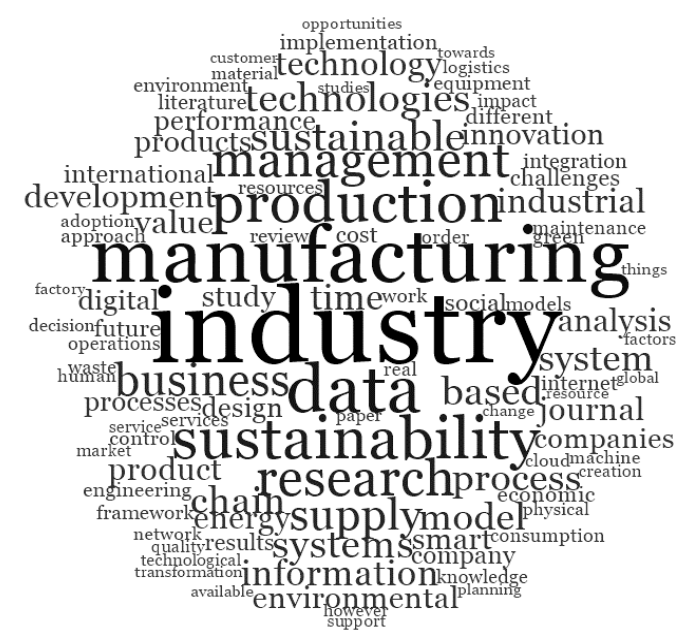

Figure 7. Word cloud of most frequent keywords in the sample.

Furthermore, a word frequency query was performed by using NVivo 12 again. In doing so, the full texts of the 89 papers were analyzed and the results are presented in Table 5 which illustrates the most frequently occurring words excluding any stop words.

Table 5. Most frequent words within the sample.

\begin{tabular}{|c|c|c|c|}
\hline Word & Count & Weighted (\%) & Similar Words \\
\hline Industry & 8913 & 1.24 & $\begin{array}{l}\text { industrial, industrialization, industrialized, industrially, } \\
\text { industrie, industries, industries', industry, industry' }\end{array}$ \\
\hline Product & 6700 & 0.94 & $\begin{array}{l}\text { product, product', production, production', productions, } \\
\text { productization, products, products', products' }\end{array}$ \\
\hline Sustainability & 5731 & 0.8 & $\begin{array}{l}\text { sustain, sustainability, sustainability', sustainability", } \\
\text { sustainable, sustainably, sustained, sustaining, sustains }\end{array}$ \\
\hline Manufacture & 5237 & 0.73 & $\begin{array}{c}\text { manufactur, manufactur', manufacturability, manufactural, } \\
\text { manufacture, manufactured, manufacturer, manufacturers, } \\
\text { manufacturers', manufactures, manufacturing, } \\
\text { manufacturing', manufacturings }\end{array}$ \\
\hline Supply chain & 4908 & 0.69 & $\begin{array}{c}\text { chain, chain', chain", chains, chains', supply, supplied, } \\
\text { supplies, supply, supplying }\end{array}$ \\
\hline Technology & 4438 & 0.62 & $\begin{array}{l}\text { technolog, technologic, technological, technologically, } \\
\text { technologies, technologies', technology, technology' }\end{array}$ \\
\hline System & 4089 & 0.57 & $\begin{array}{l}\text { system, system', systeme, systemic, systemically, } \\
\text { systemization, systemized, systems, systems', systems' }\end{array}$ \\
\hline Data & 3942 & 0.55 & data, data' \\
\hline Process & 3558 & 0.5 & process, process', processed, processes, processing \\
\hline
\end{tabular}

The search query was adjusted to include "words with the same stem". Only words with more than four characters are displayed in the figure. The results also include the number of times that the word occurs within the searched papers searched (i.e., the count), followed by its weighted percentage which illustrates the frequency of the word relative to the total words counted. A word can be part of more than one group of similar words. In this analysis, we only illustrate the most counted words, which represented $7 \%$ of the data. "Industry" $(1.24 \%)$ is the most mentioned word within the 89 papers, followed by "product" $(0.94 \%)$, "sustainability" $(0.80 \%)$, "manufacturing" $(0.73 \%)$, and "supply chain" $(0.69 \%)$.

\subsection{I4.0 and Research Methodologies}

Figure 8 illustrates the methodology distribution of the selected 89 papers. In this paper, we utilize both empirical and conceptual research approaches. Conceptual papers include papers that focus only 
on ideas, frameworks, concepts, and theories such as literature reviews of I4.0. Empirical papers are divided into five categories of different research methodologies: case studies, surveys, experiments, simulations, and prototypes. Papers that apply empirical methods focus on measurable I4.0 activities and apply primary or secondary data collection and analysis methods. The chart shows the distribution of methods among all the papers.

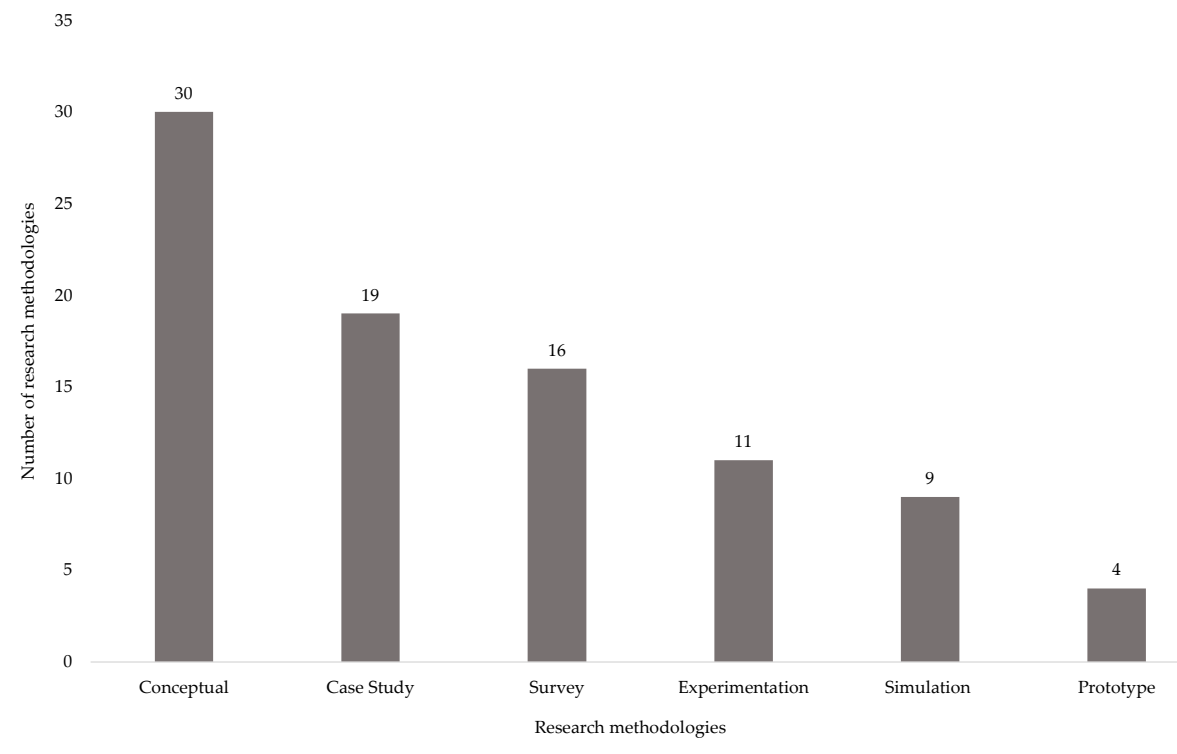

Figure 8. Research methodologies.

A total of 30 papers describe the topic at conceptual or theoretical levels. The remaining 59 papers used a case study (19), surveys (16), experiments (11), simulations (9), or a prototype (4). This indicates that approaches involving case studies and surveys are very well-suited methodologies to explore a new field such as I4.0 and its impact on sustainability [69,70]. These methods are based on primary and secondary data collection and analysis. A large amount of industrial projects are dedicated to I4.0, following the objectives of innovation action research in order to implement innovative I4.0 technologies [35].

\subsection{I4.0 Technologies}

Based on the qualitative content analysis and related I4.0 literature [9,64,71,72], the papers have been categorized into four categories according to the type of I.40 technology they discuss as shown in Figure 9 . These categories were developed by reviewing all the articles and simultaneously applying text mining to cover the technologies mentioned. The four categories where then derived based on the technological classifications from the established literature [73,74]. The distribution indicates that the most attention has been paid to smart factory technologies (57\%), including IoT, Artificial Intelligence (AI), Cyber Physical Production Systems (CPPS), and interconnected layouts. The second category constitutes studies proposing I4.0 concepts, theories, and frameworks (45\%). The third category includes data-driven technologies such as big data, blockchain, and optimization approaches (39\%) and the last category describes shop floor equipment technologies $(16 \%)$, including virtual reality, camera-based systems, automated guided vehicles (AGVs), etc.

Figure 10 presents the distribution of the I4.0 technology categories in the selected papers over the timespan of 2014-2020. From 2014 to 2016. It is observed that mainly I4.0 concepts and theories as well as smart factory technologies were studied. Interestingly, since 2017, the other technology categories have been receiving increasing interest, especially the fields of data-driven technologies (e.g., big data, blockchain) and shop floor equipment technologies (e.g., robotics, virtual reality). 


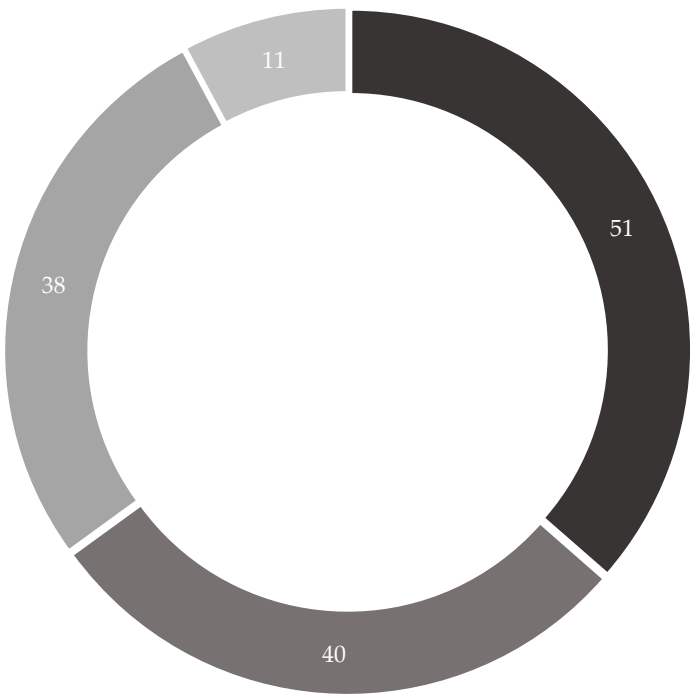

$\begin{array}{ll}\text { - Smart factory } & \text { I4.0 concepts and } \\ \text { technologies } & \text { Data-driven } \\ \text { theories } & \text { Shop floor equipment } \\ \text { technologies } & \text { techies }\end{array}$

Figure 9. Distribution of sustainable Industry 4.0 (I4.0) technologies in the papers.

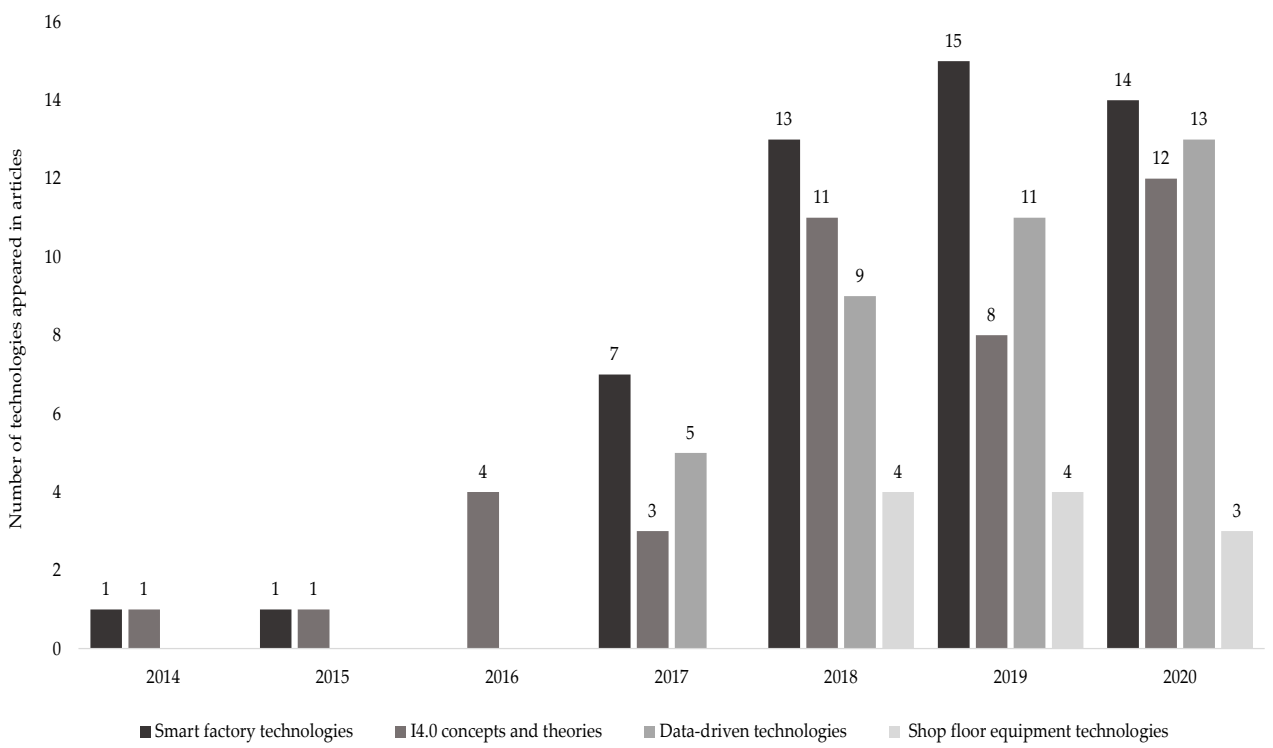

Figure 10. I4.0 technology categories over the period of 2014-2020.

\subsection{I4.0 and PEOM Research Areas}

We deliberately focus on the operations management $(\mathrm{OM})$ area because it combines all relevant resources, processes, and capabilities of a company to create value. Moreover, "operations" is the activity of resource and process management that enables the creation of products and services. The essential nature and purpose of $\mathrm{OM}$ is the same in every type of organization and is, therefore, ideal as a basis for our examination [75]. In this paper, we analyzed the distribution of papers among three different P\&OM research areas (Figure 11). Once again, a content analysis using NVivo search queries served as the main instrument for identifying the research areas. Based on the search terms "manufacturing", "supply chain" and "service" and the associated technologies within the papers, we derived the main P\&OM areas. Bias was avoided through a second iteration, which involved screening all the papers manually. The results indicate that the manufacturing domain dominates the research field with $70 \%$ of papers focusing on sustainable I4.0 technologies for manufacturing 
environments, followed by technologies for supply chains (26\%) including blockchain technologies [76], cloud applications [77], or the impact of digital transformation on circular economies [61,62,78]. The last research area involves service operations (4\%). For example, Forcadell et al. [72] analyzed the impact of corporate sustainability and digital transformation on the performance of international banks [72].

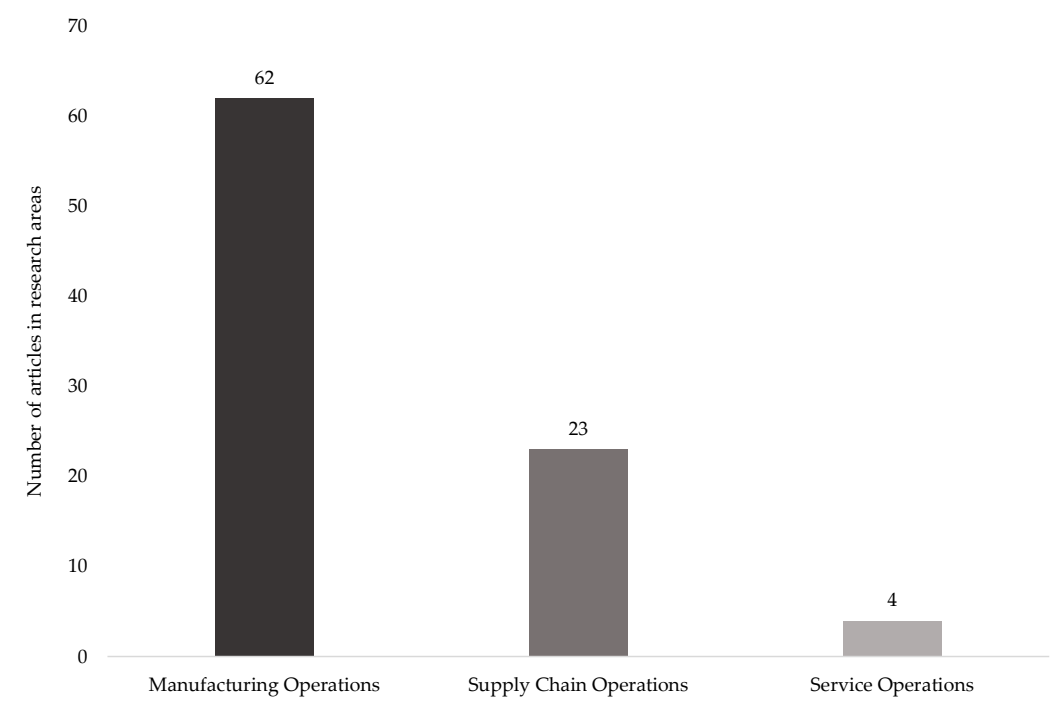

Figure 11. Production and operations management (P\&OM) research areas.

Figure 12 shows the distribution of technologies among P\&OM research areas. Please note that each paper corresponds to only one P\&OM domain. However, a paper can contain one or more technologies that are being investigated with respect to the research area being investigated. Within the area of "manufacturing operations", smart factory technologies (38\%), such as IoT applications and AI, dominate the research landscape, closely followed by concept-based and theory-based papers $(26 \%)$ and big data or optimization topics $(26 \%)$. The shop floor equipment technologies are investigated within $11 \%$ of the papers with a slight increase in the past three years.

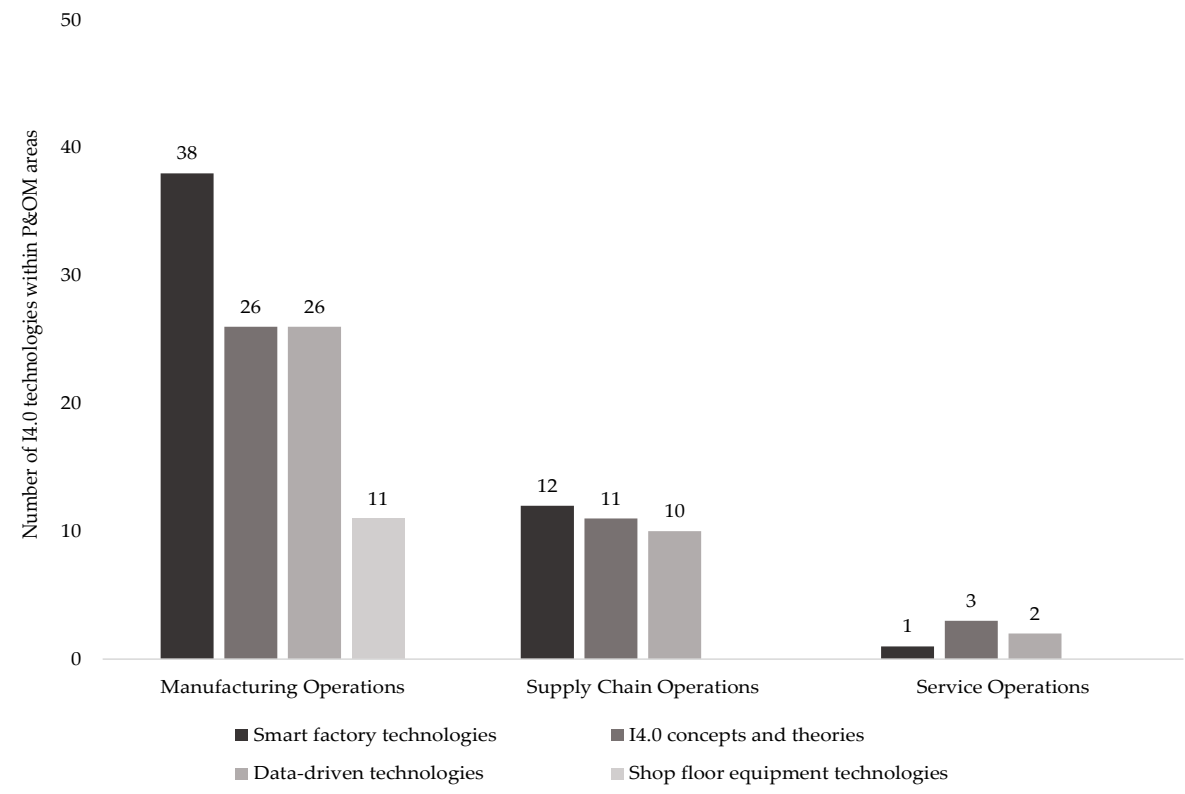

Figure 12. $\mathrm{P} \& \mathrm{OM}$ areas and $\mathrm{I} 4.0$ technologies.

While 23 papers address supply chain topics, $36 \%$ of them were focused on IoT and network interconnectivity, followed by a focus on I4.0 concepts and theories (33\%) and data-driven technologies such as blockchain 
(30\%). Technologies within service operations are distributed across conceptual/ theoretical observations $(50 \%)$, data-driven applications (33\%), and smart factory topics (17\%).

\subsection{I4.0 and Sustainability Dimensions}

Articles were differentiated into four categories based on which dimension of sustainability they focused on. The categories are named economic, environmental, and social (EcEvS), economic and environmental (EcEv), economic and social (EcS), and environmental and social (EvS). Following a predefined text search query across the sample which was crosschecked by manual screening, the results illustrated in Figure 13 were obtained. The summary of the results indicates that 47 papers address all the three pillars of sustainability i.e., they belong to the EcEvS category. Furthermore, 23 papers address solely the EcEv dimension, 12 papers discuss the impacts of I4.0 on only the EcS dimension, and 7 are dedicated to the EvS dimension. To verify these results, we additionally performed a manual screening of all papers.

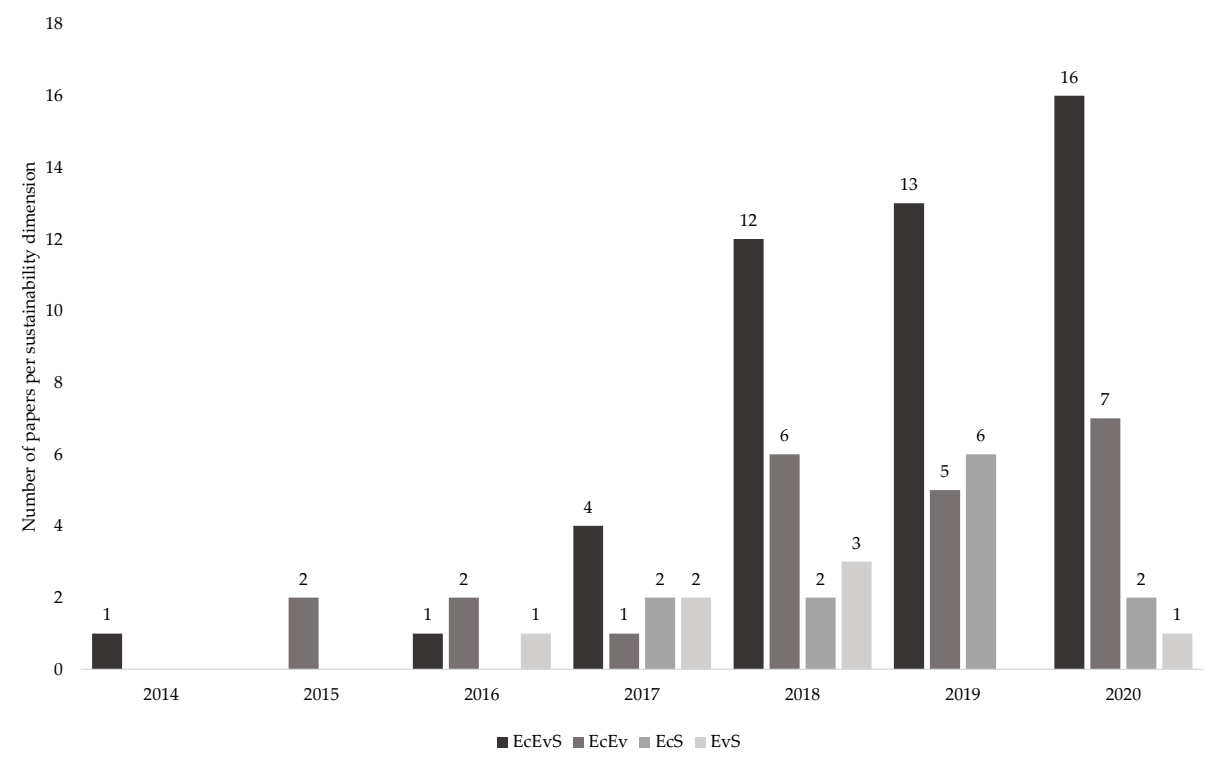

Figure 13. Evolution of sustainability dimensions in 2014-2020.

Based on the analysis, it can be stated that almost every technology entails an intersection in the economic dimension. Depending on which processes are influenced by the technology and on the direction the I4.0 innovations tends to take, the other two pillars of sustainability are then addressed. For example, many shop floor equipment technologies aim to improve efficiency in production, which also has an impact on the social dimension as employees are always involved in the individual improvement processes. For example, Bechtsis et al. [58] treat the impact of AGV systems on sustainable supply chain management [58]. The interaction of AGVs with humans and the manufacturing environment can reduce the number of work accidents or minimize human errors while simultaneously increasing operating time and productivity and reducing costs [79,80]. From an ecological point of view, electric AGVs are more environmentally friendly in various areas as they are more energy-efficient than vehicles with internal combustion engines [58,81].

Another inherent effect of the analysis is that investigations and directions of research regarding the social dimension are shown to have increased in the last three years (i.e., 2017-2020). A substantial number of papers deal with human-machine interaction, change of work behavior, or collaborative manufacturing due to technological changes within manufacturing environments [7,82-85].

The existing discussion in the literature focuses on different I4.0 technologies. As stated in the section "Sustainable I4.0 technologies", we identified four different technology categories, i.e., I4.0 concepts and theories, smart factory technologies, data-driven technologies and shop floor equipment technologies. 
A review of the most recent years shows a clear shift from theory and concept development to implementation projects. At the beginning of the I 4.0 trend movement, technologies were discussed very superficially and casually. In recent years, however, the degree of implementation of individual cases has risen sharply, making it possible in some cases to assess the impact of individual technologies. However, a financial or a quantitative assessment of the technologies is still lacking in many respects. Many articles qualitatively deal with the topic and most authors collect results based on surveys and case studies to illustrate the impact of I4.0 on business structure, society, and technological development $[86,87]$.

\subsection{I4.0 Technologies and Sustainability Dimensions}

This section presents an overview of the I4.0 technologies involved in the redesign or improvement of manufacturing processes and their impact on the dimensions of sustainability. The technologies observed in the papers were analyzed based on their impact on the dimensions of the TBL, see Table 6. In total, 70 identified technologies impact the EcEvS category, followed by 41 for the EcEv category (and 18 for the EcS category. Only 11 technologies were identified that influence the EvS dimension.

Table 6. I4.0 technology distribution among the sustainability dimensions.

\begin{tabular}{cccccc}
\hline TBL Dimension & $\begin{array}{c}\text { Smart Factory } \\
\text { Technologies }\end{array}$ & $\begin{array}{c}\text { I4.0 Concepts } \\
\text { and Theories }\end{array}$ & $\begin{array}{c}\text { Data-Driven } \\
\text { Technologies }\end{array}$ & $\begin{array}{c}\text { Shop Floor Equip. } \\
\text { Technologies }\end{array}$ & Total \\
\hline EcEvS & 24 & 25 & 20 & 1 & 70 \\
EcEv & 16 & 7 & 12 & 6 & 41 \\
EcS & 7 & 4 & 4 & 3 & 18 \\
EvS & 4 & 4 & 2 & 1 & 11 \\
Total & 51 & 40 & 38 & 11 & 140 \\
\hline
\end{tabular}

\subsubsection{I4.0 Concepts and Theories}

I4.0 concepts and theories are most often discussed based on all three dimensions. Many papers focus on frameworks that cover all dimensions of sustainability. I4.0 offers an opportunity to reconcile the objectives of sustainable development with the ongoing digital transformation in industrial development. Some articles focus on frameworks to illuminate I4.0 from a socio-economic perspective while analyzing the relevant theory and practical developments [64,71,73,88]. Others such as Garcia Sonia et al. [87] propose a framework that illustrates the transition from traditional business models to sustainable digital business models. From a strategic perspective, I4.0 provides opportunities in terms of a transformation of value propositions through a business model innovation process [87]. The proliferation of disruptive technologies deployed in the I4.0 context has caused many companies to shift away from traditional business models and enter innovative, sophisticated, and agile digital ecosystems [87,89]. It is still not possible to estimate the actual effects of such a corporate transformation. On the level of macroeconomic strategy, global impacts can be assessed relatively accurately. However, the fundamental impacts will take place at the microeconomic, tactical, and operational levels within the company. The impact evaluation of I4.0 still poses challenges for science and its practice and represents a gap in research $[29,63,90,91]$. Furthermore, distinctions must be made among the technologies that have been investigated. Critical key technologies, such as cloud computing, modularization, or equipment connected to IoT, have already passed the theoretical phase and have reached market maturity and are therefore not often considered within conceptual papers. However, innovative technologies such as robotics, augmented reality, factory virtualization, or additive manufacturing are still in the developmental stages. Therefore, many concepts and theory papers deal with these technologies [64,92,93].

\subsubsection{Smart Factory Technologies}

The influence of smart factory technologies on the sustainability dimensions is the largest. A huge amount of papers focus on smart factory technologies including the implementation of key enabling 
technologies such as IoT, CPPS, AI, smart factory layouts, energy-efficient buildings, nanotechnologies, and advanced materials $[78,94,95]$. All these elements are integrated into the physical infrastructure of a factory in order to create a smart manufacturing environment that goes beyond the physical location and affects all value creation processes [56]. The smart factory is a core aspect of the digital transformation campaign. It is primarily about networking plants, machines, and the people who work in the respective production environment with the help of software [96]. This technological development serves to create more intelligent forms of communication and automated processes. An increase in the networking of the internal value and process chain will ultimately lead to production networks developing in the same direction [97]. A production network consists of the entire value chain, from the suppliers to the customers. A smart factory is made up of a number of core technologies that were created in the course of the development of I4.0. In recent years, there has been an increase in computing power, storage capacity, and the development of cloud services and platform concepts [98].

The basic idea of smart manufacturing environments is the real-time capable, intelligent, horizontal, and vertical networking of people, machines, objects, and information and communication technology systems for dynamic management of complex production systems $[99,100]$. For this purpose, all tools, products, and systems can be equipped with integrated computing power. This enables direct data acquisition from their environment, simultaneous processing and forwarding of this data, and selforganization within the network [101].

Smart factory technologies also focus on the social dimension. A continuous improvement process, which is supported by well-developed knowledge management in the company, leads to ongoing training and qualification of production employees. A higher degree of automation and visualization relieves the employees from monotonous tasks and assists them in complex processes [35]. Smart factory technologies constitute the heart of Industry 4.0; therefore, the integration of these technologies is not limited to the manufacturing systems. Moreover, a horizontal integration for connecting all functions across the global value chain is a necessity $[100,102]$.

\subsubsection{Data-Driven Technologies}

The third technology category, namely data-driven technologies, includes big data applications, data analytics methods, business intelligence systems, simulation blockchain, etc. The massive increase in the availability of data allows the optimization of models to enhance error analysis and the prediction of specific situations to set up early counteractive measures [103]. I4.0 is all about collecting data from various sources and then unleashing the necessary analytics, machine learning, or AI in order to streamline production processes $[59,104,105]$. The application of data processing allows for the integration of analytical systems to enhance sustainable decision-making processes within manufacturing environments and supply chains [86]. Better decisions may result in improved operational efficiency and cost reduction [106]. Data-driven decision support systems such as business intelligence systems have the goal of increasing the quality of the information that is available for decision-making induced by the improvement of data processing [103]. Others such as Culot et al. [107] stated that process and product data will grow in importance. Data are a crucial factor in production and supply chain operations. Furthermore, the monetarization of data plays an incremental role within industrial value chains, based on its increasing relevance for business operations [107]. Sustainable manufacturing is positively mediated through the use of sensors, intelligent algorithms, and actuators to permit data collection in the manufacturing environment [108]. Another I4.0 key enabler related to data-driven technologies is blockchain technology. The information network of a blockchain allows in-depth management of material and products along supply chains. Historic product characteristics can be saved in the blockchain, which allows users to identify the origin, quality, and lead time of the product $[76,83,109]$. Furthermore, sustainability data such as green quality, recyclability, and the carbon footprints of products can be tracked [76]. In this context, it should be noted that transparency and traceability of product and process information on the basis of the available data represent enormous value for company performance and competitiveness. 


\subsubsection{Shopfloor-Equipment Technologies}

Shop floor technologies have received an increase in research interest in recent years. The call for more flexibility and agility within production systems in order to create customized products led to a focus on flexible human-centered production assisted by innovative technologies [110]. The vision of Industry 4.0 has always been to focus on building a human-centric environment [36]. In order to set up a cognitive automation environment, it requires an interconnected shop floor system [111]. Technologies such as robotics, virtualization, and visualization of machines or virtual reality are fundamental technologies to establish interactive, intelligent networks. New, innovative solutions and old, proven systems have to function in coexistence. The new manufacturing equipment is characterized by the application of highly automated machine tools and robots, e.g., human-machine interfaces, enable collaborative working environments [112]. There is a huge impact on the social dimension within this area. Employee behavior is changing to the extent that they have to act in a multidisciplinary fashion. Different technologies require informal expertise and knowledge that goes beyond previous activities. A combination of technology and expertise will enable companies to unleash the full potential of the interactive and collaborative capabilities of these systems [64,113]. Initial studies in the industry 4.0 research field claimed that jobs in the manufacturing sector would be at risk because a large number of processes would be fully automated. The number of workers would decrease [112,114]. From today's perspective, we know that this is not the case. A large proportion of the technologies implemented are used as assisting and not replacing technologies. Today, we know that technology creates jobs and only replaces tasks $[115,116]$.

\subsection{PEOM Areas and Sustainability}

The final analysis in this section refers to the P\&OM areas and their respective associated sustainability dimensions in the papers. Please note that each paper is assigned to one P\&OM area and at the same time only to one sustainability category.

As illustrated in Table 7 most publications are located in the area of manufacturing operations. Many of these articles focus on the EcEvS category, meaning they influence all the dimensions of sustainability. Interestingly, papers associated with supply chain operations gain an increasing focus on I4.0 applications that improve EcEv issues. For example, Fatorachian and Kazemi [21] stated that increased transparency resulting from I4.0 applications can lead to more efficient management of order fulfillment. Access to Real-time information can have a positive impact on transportation by enabling disintermediation, which reduces fuel consumption and gas emissions [21,117]. Other technologies such as blockchain and IoT are key enabling technologies for the activities of green supply chains, especially in procurement. Eco-friendly procurement ensures lower energy consumption and more efficient waste disposal $[76,118]$. However, when taking into account the papers regarding servicer operations which are rather limited in this analysis, to only four articles, there is a clear focus on the EcS category.

Table 7. P\&OM area and sustainability dimension.

\begin{tabular}{cccccc}
\hline P\&OM Area & EcEvS & EcEv & EcS & EvS & Total \\
\hline Manufacturing Operations & 35 & 14 & 7 & 6 & 62 \\
Supply Chain Operations & 11 & 9 & 2 & 1 & 23 \\
Service Operations & 1 & & 3 & & 4 \\
Total & 47 & 23 & 12 & 7 & 89 \\
\hline
\end{tabular}

For example, the availability of massive data from customers creates asymmetric information for banks. Digitization reduces information asymmetries by improving transparency and intelligent data processing, which in turn leads to more accurate predictions of customer behavior [72]. In conclusion, there is a clear trend along all $\mathrm{P} \& \mathrm{OM}$ research areas towards the consideration of all sustainability dimensions. 
A detailed overview of the papers' authors, therein-affected sustainability dimension, and the respective P\&OM research area are presented in Appendix A (Table A1).

\subsection{Review Discussion and Findings}

The results presented in the literature review show different research opportunities in the field of sustainable development in I4.0. The findings within the descriptive statistics and the qualitative content analysis served for answering $R Q 1$ and partially $R Q 2$. The 89 papers were scanned and analyzed for I4.0 and its impact on sustainability in P\&OM. This served to answer $R Q 1$ and to present various I4.0 technology categories, its impact on $\mathrm{P} \& \mathrm{OM}$ research areas and on sustainability dimensions. Sustainability has received increasing attention in the I4.0 literature. A tremendous amount of papers are investigating key enabling technologies that will allow industries to retain competitiveness and capitalize on new markets. A huge effort has been made in recent years particularly in Europe to drive I4.0 forward. Europe's industry is facing various challenges, such as increasing global competition and the need to remain energy and resource efficient. Investments in innovation are therefore essential to meet these challenges and sustainability is at the top of the political agenda to be met by 2035 [65,119]. Sustainable development is key for Europe's manufacturing industry. The improvement of engineering leads to more flexible production systems, sustainable processes, and improved production processes [65].

Kamble et al. [64] pointed out that the topic of sustainability in I4.0 receives too little attention. Above all, the authors refer to the need for more studies in the areas of resource and energy efficiency as well as workforce safety. Intelligent devices and manufacturing systems have the potential to reduce waste, overproduction, and energy consumption. In 2020, the state-of-the-art in this area looks somewhat different. The systematic literature review in this paper shows there have been a lot of developments in this field of research in the last two years.

The harmonization of I4.0 and sustainability plays an important role currently in the field of P\&OM. Manufacturing industries recognized that the synergies of these two streams enable the efficient development of the entire value chain $[77,120]$. Sustainable value creation is currently being promoted very strongly in the literature. Various studies are focusing on one or more dimensions. Stock et al. [83], for example, refers to the ecological and social dimensions in their study. Their case assessment revealed that some factors of value creation, such as energy efficiency, waste reduction, or better working conditions as well as information transparency, etc., can influence the environmental and social dimensions in both positive and negative ways [83].

In particular, given the dimensions of TBL, the picture has shifted in favor of all three pillars of sustainability (economic, environmental, and social). Interestingly, the existing research activities focus on an economic-environmental viewpoint while considering very superficially the social impacts of I4.0 [121,122]. Although, with the increasing introduction of human-machine-centered work environments, the impact on the social dimension is becoming increasingly attractive and, above all, easier to assess. Nowadays, manufacturing environments and industries call for highly skilled workforces with expertise in data science, new materials, equipment, and digital technologies [122,123]. Overall, the economic impact is the most influential factor in I4.0 developments. The reduction in operating costs and the improvement of manufacturing speed and production as well as process quality through end-to-end digital integration is one of the major drivers for I4.0 investments [93,124,125]. However, these investments must be weighed against the high costs of implementation [64].

\section{Focus Group Discussions}

To underpin the theoretical findings, we applied a second methodology. As part of investigating the current state of research (RQ1), we conducted focus group discussions [126] with participants from the project consortium "Power Semiconductor and Electronics Manufacturing 4.0" (SemI40). The first picture is drawn by this method by evaluating how and if technological development in the context of I4.0 applications influences sustainability. We can assume that technological progress has a direct impact on every dimension of sustainability. In the end, we have to measure and evaluate 
these impacts. In our investigation, we set the focus on all pillars of the TBL: economic, environmental, and social performance. The results of the literature review illustrate a gap within current research activities in the investigated field. Moreover, impact measurement and evaluation of I4.0 technologies on internal sustainable value chains and processes is an emerging challenge (RQ2).

In order to ensure the generalizability of the focus group findings, we ensured the representativeness of the respondents. Respondents were recruited independently of each other but from the same industry. The heterogeneity within each focus group ensured unprejudiced responses and therefore, partial generalizability of the results. In our study, several research centers and industrial partners (anonymized) from the SemI 40 project consortium contributed to the generation of new ideas and the identification of the needs and the several future expectations with respect to the development of I4.0 in the semiconductor industry. Within this focus group constituting 20 persons from 14 different institutions, the following five questions were discussed:

1. Q1: How would you define sustainability in I4.0?

2. Q2: In which areas will I4.0 have an economic, environmental, and/or social impact?

3. Q3: What are the suitable and the existing performance indicators and approaches to measuring the economic, environmental, and/or social impact of I4.0?

4. Q4: Should new performance indicators be developed to measure the economic, environmental, and/or social impact of I4.0?

5. Q5: Where do you foresee significant economic, environmental, and/or social improvements or consequences for your organization through 14.0 within the next 10 years?

Participating focus groups were listed using alphabetic initials (A, B, C ... ), and the recorded statements are clustered around the respective question. Figure 14 includes an example of responses from focus group A to each respective question. The full list of focus group discussion results is attached in the Appendix B section (Tables A2-A6) of this paper.

\begin{tabular}{|c|c|c|c|c|c|}
\hline $\begin{array}{l}\text { Focus } \\
\text { Group }\end{array}$ & Q1 & $\mathrm{Q}^{2}$ & Q3 & $\mathrm{Q} 4$ & Q5 \\
\hline A & $\begin{array}{l}\text { A Smart and flexible production } \\
\text { environment with components } \\
\text { interacting dynamically (humans, } \\
\text { material, machines) } \\
\text { Intelligent networks, linkage of } \\
\text { human to machine and } \\
\text { technological environment }\end{array}$ & $\begin{array}{l}\text { Strategic level } \\
\text { - Definition of policies for } \\
\text { dynamic systems } \\
\text { - Flatten organizational } \\
\text { hierarchies } \\
\text { - New management roles } \\
\text { - Increase of educational } \\
\text { measures } \\
\text { Tactical level } \\
\text { - Safe and protected } \\
\text { manufacturing environments } \\
\text { - Better error handling } \\
\text { Operational level } \\
\text { - Better process monitoring } \\
\text { - Cycle time optimization } \\
\text { Employees will have more } \\
\text { responsibilities }\end{array}$ & $\begin{array}{l}\text { Economic } \\
\text { - Return on Investment (ROI) } \\
\text { - Cycle time } \\
\text { - System Availability } \\
\text { - Expan reliability } \\
\text { - Quality measures } \\
\text { - Number of returns } \\
\text { Environmental } \\
\text { - Energy efficiency } \\
\text { - Waste reduction } \\
\mathrm{CO}_{2} \text { emission } \\
\text { Social } \\
\text { - Relation of high vs. low } \\
\text { - Eualification jobs } \\
\text { - Cmployee satisfaction } \\
\text { - Emploe of work behavior } \\
\text { - Level of eductuation } \\
\text { - Emation. }\end{array}$ & $\begin{array}{l}\text { Economic } \\
\text { - Flexibility measures } \\
\text { - Internal maturity level } \\
\text { - Activity based costing key } \\
\text { performance indicators (KPIs) } \\
\text { - Implementation Costs vs. } \\
\text { Benefit } \\
\text { Environmental } \\
\text { - Smart meters } \\
\text { - Energy efficient layout } \\
\text { structures } \\
\text { Social } \\
\text { - Control frequency and work } \\
\text { - Maad } \\
\text { - Measurement of new job } \\
\text { profiles } \\
\text { - Efficiciency of employees } \\
\text { - New skills } \\
\text { - Influence level of IoT on } \\
\text { employee } \\
\text { Employee satisfaction }\end{array}$ & $\begin{array}{l}\text { Economic } \\
\text { - New projects \& concepts } \\
\text { - New technologies ensure } \\
\text { profitability } \\
\text { - Company growth } \\
\text { - New company structures } \\
\text { - Higher level of innovation } \\
\text { - Increase of company networks } \\
\text { - Reinforced EU networks. } \\
\text { Environmental } \\
\text { - Energy efficiency } \\
\text { Social } \\
\text { - More attractive student } \\
\text { - programs } \\
\text { - Incter education programs } \\
\text { In technical education }\end{array}$ \\
\hline
\end{tabular}

Figure 14. Extraction of focus group discussions (Example: Group A).

\subsection{Findings from Focus Group Discussions}

In order to obtain valuable findings from the focus group discussions, we conducted a content analysis of the recorded results for each group (A-E) [127]. To verify the statements and to avoid bias, the coded analysis was then discussed in an expert panel, which included researchers associated with the evaluation workgroup of the project SemI40 [128]. The distinction between statements truly associated with stated questions and statements of an interpretative nature (e.g., what sounds interesting for participants?) has proved challenging. The theoretical and descriptive validities are based on the quality of the responses (intensity, context, and the relation of responses) and not their 
frequency with respect to the research questions stated. The final step includes the disaggregation of the individual group results into subunits and the construction of a landscape that concludes all answers to the specific questions. The subunits are based on the strategical, operational, and tactical levels of operations, followed by the classification of responses associated with the economic, environmental, or social dimension of sustainability. Validity refers to the inferences drawn from the study's context and statements of the respondents [44,127]. For example, when extracting responses associated to RQ2 from the sheet, we were able to identify five specific digitally influenced areas: (1) human resources (HR), (2) organizational and operational processes, (3) manufacturing and/or production, (4) logistics and (5) IT and shop floor. Examples of the affected strategic, tactical, and operational impacts are as follows: (a) Strategic: definition of policies for dynamic systems, flattening of organizational hierarchies, new management roles and increases in educational measures, (b) Tactical: safe and protected manufacturing environments, better error handling and (c) Operational: better process monitoring and optimization of cycle time and employee responsibilities. A special focus was set on statements with respect to the social dimension. Furthermore, we are able to extract the respective impacts on the three dimensions of sustainability (Q3-Q5). The focus groups mentioned the following aspects, which will be directly affected by digitalization cases generated in the I4.0 project. The listed economic, environmental and social impacts served to answer $R Q 2$.

\subsubsection{Economic Impact}

Most of the companies deal with improvements in the production process. Therefore, we were able to identify some overlaps concerning the economic impact when comparing the focus group results with each other. When assessing the supply chain of an organization, several impacts through single process improvements are evident. Both internal and external improvements can occur. For example, the early and precise detection of faulty items using sensors and intelligent algorithms results in better information for the upstream and downstream departments of the company. The reduction in lead time allows operating departments to increase their throughput rate. The company can react faster to uncertainty in order fulfilments and give adequate information to the customer, which results in better service performance and customer satisfaction. Costs are also expected to be affected. The company can reduce operating and production costs if the overall product and process quality is improved. All companies see improvements in the overall cycle time and times to market. Experts stated that I4.0 applications help to mitigate flexibility along the internal value chains and enable faster reactions to market fluctuations. For example, an expert from Group D stated that "... variable capacity scenarios within the production lines mean an increase in productivity and reduction in production costs, leading to better responses to customer requirements in the short term and an acquisition of a better position in the market place". Furthermore, the response time in terms of accidents or cyber-crime issues can be reduced to a minimum by applying new IT-security solutions. An expert statement from Group B is that "Future data communication is to provide the appropriate security mechanisms, to mitigate potential attacks and to reduce the risk of successful cyber-attacks by cyber criminals. Therefore, the technical and organizational aspects have to be taken into account."

\subsubsection{Environmental Impact}

In semiconductor manufacturing, energy is required to process the silicon wafers in the production line. To run process equipment and tools in a semiconductor facility, $40 \%-50 \%$ of the total energy consumption is needed. For improving energy efficiency at the production level, several sustainable practices can be adopted by the utilization of IoT technology (e.g., avoiding peak time, integrating energy data into the production schedule, or the automation of environmental controls) [129]. For this purpose, the energy consumption in the individual manufacturing plant must be measured and the relevant energy flows must be understood. Production costs can be reduced by the application of more energy-efficient manufacturing systems. One participant of Group A mentioned that "... competitive advantage will increase by the acquisition of sustainability and environmental certifications 
through optimal operated tools with fewer pollutants and emissions." This leads to price advantages against competitors and strengthens the competitiveness of companies. By acquiring sustainability and environmental certifications, the company's products will also differ from those of competitors. Modern production equipment and optimally operated machines will emit fewer pollutants and manage more carefully the limited resources in order to protect the environment. For example, an expert from Group E argued that "The use of new control and optimization tools will improve capacity utilization and therefore, improve energy consumption." Furthermore, an increase in raw materials and energy prices and a simultaneous decrease in resource availability lead to bottlenecks in productivity. The dependence for resources on Europe by other countries is a problem concerning the competitive advantage for future development $[130,131]$.

\subsubsection{Social Impact}

Several HR experts within the focus groups stated that organizations will need more experts and qualified engineers in specific fields as digitalization will lead to an increase in needed know-how and competencies. Multidisciplinarity will become more important. New job models and functions will emerge and companies will have to set up new educational measures. An HR expert from Group $\mathrm{C}$ argued that "The development of new technologies will change the expert knowledge used in the semi-automated decision process, which causes different requirements of competences from the employees." Another aspect that was raised by analyzing several comments of the HR experts was the impact on social skills, e.g., the change in interpersonal contact, less human-to-human communication, impact on work satisfaction, different employment structures, and the use of assistance systems. Preventive maintenance might trigger implications regarding the flexibility of the organizational structure as well as for the working time model that again reduces costs and serves as a compensatory for time-off. The maintenance times of machines will change, i.e., the maintenance is forwarded to the standby times of the production lines. Another production manager from Group D stated that "... intelligent software applications based on automated quality inspection systems reduce monotonous tasks in terms of manual quality inspection, and therefore, increase the employee satisfaction and decrease the individual stress-levels of operators." Related to improved process control, the manual revision of false alarms is a very challenging task and should be reduced. Expensive engineering hours taken to rearrange the program in the production process will be reduced. The use of mobile robots supports the operators regarding physical liability or may even free them from physically demanding tasks. With the introduction of assistance tools such as image recognition or shop-floor visualization, the strenuous and monotonous quality control activities of employees previously responsible for manual testing are changing into a more varied and thus more satisfying activity.

\subsection{Discussions and Future Research Directions}

Finally, based on this analysis, we introduce a conceptual model for a new TBL approach that considers the technological development along with the social, economic and environmental dimensions of sustainability.

The results of our investigation show that the technological aspect is the focus of the current research activities. Technological progress influences each of the three dimensions of sustainability [132]. In the study of Felsberger and Reiner [132], the authors focused on the impact evaluation of digital transformation projects by conducting explorative multiple-case study research. The results of the study contributed to how to evaluate value chain process improvement after innovative I4.0 applications.

Furthermore, the authors underline the criticality to establish innovative, technical solutions in ongoing business operations to enhance operational benefits. Therefore, seven industrial cases within a specific application area of the semiconductor industry were analyzed. The main objective was to analyze the expected impacts of the cases on the three TBL dimensions.

In the present paper, we refer to the conceptual TBL model by identifying different internal as well as external influencing factors and expected impacts of I4.0 on sustainability based on the results of focus 
group discussions. Thus, the concept will be further developed and interdependencies between the dimensions of sustainability, triggered by technological development, will be anticipated. The results of our analysis show that the technological aspect is in the focus of the current research activities.

The interdependency between the social, economic, and environmental dimensions is at the core of sustainability [14]. For example, Carter and Rogers [133], describe that sustainable supply chain management comprises the management of material, organization, information, and the risks as well as the cooperation of all supply-chain participants to reach transparency that interacts as a link between the economic, social and environmental issues $[15,133,134]$. The same picture comes up for organizational sustainability and sustainable operations, which consist of these three core components: the economic, environmental, and social performance [135]. Figure 15 shows a representation of the integration of a fourth dimension: technological development. Technology has direct and indirect influences on sustainability across the whole value chain. Technological progress affects the whole organization and the pursued strategy of a business unit. Under this condition, we include the technological shift induced by the fourth industrial revolution. Meanwhile, despite a high level of automation and increasing flexibility in production, inefficient processes still lead to a waste of resources. Digitalization has the potential to revolutionize value creation by building new and enhancing existing capabilities, while increasing productivity. Through the improved use of networked data, human-machine collaboration and intelligent products, digitalization becomes an enabler of gains in productivity and can sustainably strengthen the competitiveness of a company [136]. Technology alone will not create value for the customers, society and businesses. Above all, the exploitation of the business processes and planning methods facilitated by technology will lead to a comprehensive improvement of the value chain [137]. Significant economic, environmental and social improvements or consequences caused by 14.0 within the next 10 years such as that which follows were identified using the focus group research:

1. Economic improvements-a decrease in production time through automated decision-making, faster and more reliable production systems, rapid learning cycles, increase in automation and communication, different types of value chains (more complexity and transparency)

2. Environmental improvements-energy efficiency, less fuel consumption, waste reduction, reduction in $\mathrm{CO}_{2}$ emissions, reduction of hazardous accidents.

3. Social improvements-an increase in knowledge management, new processes will change work behavior, new job systems, increase in company networks, dynamic supply chain networks, reinforced regional and European networks and more risks like new challenges for society, fewer operations, reduction of specific job functions.

The findings of this paper have both academic and managerial implications. The findings show that sustainability in I4.0 is an emerging field. Although a high number of conceptual papers are to be found, research is shifting towards the application of mixed method approaches to generate valuable qualitative as well as quantitative insights within their studies. The field of I4.0 is undergoing rapid development but is still a aspiring research area and publications may thus not always be found in highly ranked journals. Therefore, we aimed to increase the credibility in our results and triangulated our data by conducting focus group discussions that allows us to identify challenges and future research opportunities. Meanwhile, I4.0 applications with high maturity levels are already implemented in the running operation of companies, which allows a better investigation of the effects on sustainable business performance in the P\&OM environment. Moreover, there is room for researchers and practitioners to realize the need of simultaneously covering EcEvS aspects of sustainability in order to create sustainable manufacturing environments. Academics and practitioners benefit from a systematic overview of relevant articles in the research field and may use the provided information for future research directions. The transformation of business processes is a crucial step for organizations in order to stay competitive over time [138]. By complementing these results with the focus group discussions, we have been able to show that several economic, environmental, and social impacts already exist and are expected to increase within the next years. The management science community 
may address I4.0 as a promising context, which allows for further investigation and refinement of theories and already implemented systems. Consequently, the differentiation of companies and a continuously improvement of value-adding business processes will help to make effective decisions to create a positive impact on the value chain and to make operations more profitable [139]. Our research supports the idea that powerful digital technologies enhance the overall business competitiveness.

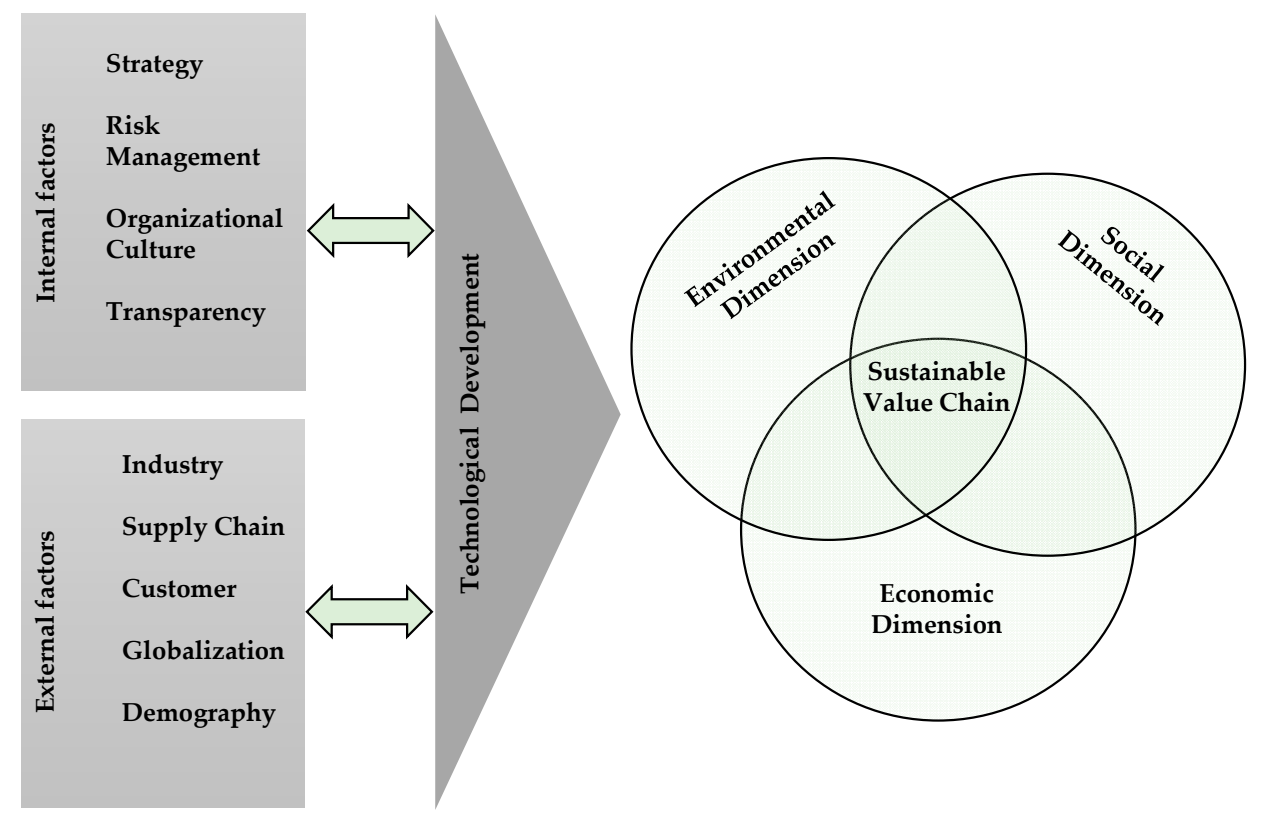

Figure 15. Influencing factors for sustainable I4.0 (cf. Felsberger and Reiner [132]).

The research framework illustrates several research gaps in sustainable I4.0, in particular, with regard to the various technical innovations in the individual OM areas and their effects on processes, resources, and planning structures. The number of conceptual papers is still too high. This is partly due to only a certain proportion of the manufacturing industry having implemented I4.0 in its entirety, or rather we are still at the beginning of the digital transformation campaign. Furthermore, documentations of technologies that have already been successfully implemented are scarce and their effects in an economic, environmental, and social scope have not yet been properly assessed. More research beyond the traditional approaches is required.

Future research projects will mainly aim at the evaluation of individual technologies. The framework will serve as a basis for evaluating the interactions and the effects of digitization on the company's capabilities.

\section{Conclusions}

The results of the systematic literature review and the focus group discussions contribute to the evaluation of sustainable manufacturing and supply chain process improvement after adopting I4.0 technologies. This study provides an overview of the state-of-the-art of scientific activities in this research area. Furthermore, it will fill potential gaps in the literature concerning dependencies between the evaluations of the economic, environmental, and social impact in the context of the adoption of different new technologies.

However, this paper comes with certain limitations. The literature review only considers journal articles; conference papers and books could also have been included in the study. In our analysis, we did not consider a co-citation map, page ranks, or data clustering. Other databases such as Scopus or Google Scholar could have given different results or provided the papers of more relevant journals. Given the nature of the topic, a huge amount of literature reviews are published yearly. Therefore, our study focused only on the specific field of sustainability within I4.0. In detail, a more comprehensive quantitative and qualitative analysis of the overall I4.0 context, including other research areas, despite 
the P\&OM domain could be carried out to validate the results of our findings. Further studies are needed to generalize and validate the results within our findings of the focus group discussion. We only investigated the ECS industry. Other business sectors could be the subject of further research to generate in-depth insights from other perspectives. Furthermore, we acknowledge that there are limitations to the data used in this article. In the second part of the study we collected data through focus group discussions, which might have allowed for overrepresentation of some research participants, dominating the conversation, and therefore influencing the overall group dynamics. To counteract this problem, we have recorded every single statement made by the respective actor. In addition, moderators were used to maintain the group dynamics. A further limitation is the reluctant response of group participants concerning sensitive topics. Since the group operates in the same industry sector, competitors were also present. This might lead to the situation that certain topics were not discussed in an open manner. Therefore, selective individual interviews or surveys could consequently provide better data.

Further limitations of the study include the fact that no national policies or programs and overall industrial developments were examined. A comprehensive analysis of the results, generated impacts or investment returns of EU projects or specific governmental I4.0 programs from leading I4.0 countries such as Germany, China or Brazil would offer very fruitful content for potential discussions. Other industry-driven, collaborative projects outside the ECS domain deal for example with flexible and autonomous manufacturing systems based on additive manufacturing (project FASTEN [140]), or cybersecurity aspects of I4.0 (project COLLABS [141]). Nevertheless, there is still a lack of consensus on which technologies compose I4.0. In our study, we identified four categories based on the technological classifications from the established literature. The most attention has been paid to smart factory technologies, outlined in Section 5.6.2 of this paper, followed by I4.0 concepts and theories, data-driven technologies, and shop floor technologies. Investments into smart factory technologies leads to the highest impact among EcEvS aspects. The combination of information technologies and manufacturing equipment seeks to achieve a high level of operational efficiency and create new potential for firms changing strategic management, which may lead to improved overall sustainable competitiveness [35,142,143].

Furthermore, Dalenogare et al. [144] observed the expected impact of I4.0 by using surveys: some topics of I4.0-as for instance big data or additive manufacturing-are expected to play a major role both in terms of product development and operational technology, while for example the contribution of flexible manufacturing lines is not yet clear. Comparing these results to the European Union plan of I4.0 integration, analogies are evident. Ciffolilli and Muscio [33] identified key enabling technologies by using data from European regions' participation in collaborative research projects promoted by the 7th Framework Programme for research and innovation (FP7) to support the competitiveness of the European manufacturing domain. The analysis is based on data from the original database of 10.000 research cooperation projects funded by FP7. In general, Europe's I4.0 is focused on the definition of novel products, processes and technologies to reorganize sustainable value chains. The authors state that the main enabling technologies of I4.0 are advanced manufacturing solutions (interconnected, easily programmable collaborative robots and sensors), additive manufacturing ( $3 \mathrm{D}$ printers connected to digital development software), industrial internet and cloud (multidirectional communication between production processes and products), and big data and data analytics to optimize products and processes [33]. I4.0 is assisting a broader renewal of the role of manufacturing within national economies [65].

The limitations and implications of this study further open new research directions for future studies. One research gap is the quantification of I4.0 implementation projects. The development of methods and approaches for an overall financial and macroeconomic assessment of I4.0 should be addressed more in research. There are hardly any publications that quantify the costs of implementation or the actual benefits or returns from investment in I4.0 applications. For our research, more detailed decoding of the focus group discussions and further investigations in terms of expert interviews will be the next activities. The scientific contributions are relevant in order to highlight the importance of sustainability with respect to innovative business models for I4.0. 
Our study aims to give answers to the underlying research questions ( $R Q 1$ and $R Q 2)$ and to identify directions for future research based on the results of the systematic literature review and the focus group discussions. In particular, we identify how different effects caused by a technological shift influence the dynamic interaction of the sustainable supply and value chains of companies. The impact evaluation is crucial to justify future investments in I4.0 management implications and research and development activities; moreover, to generate an outlook for upcoming challenges and changes (RQ2). Technology is forcing future manufacturing systems and I4.0 technology adoptions can help secure a sustainable production environment. In recent years, the intensified competition among European manufacturing companies has resulted in a concentration on the optimization of operational activities in order to remain competitive with Asia and the USA. Increasing demands in service requirements such as customizability and flexibility determine improved operational processes [145]. The integration of intelligent and smart systems, digital technology adoptions and new management approaches in the context of I4.0 is still an emerging topic due to sustainable production environments.

Author Contributions: Conceptualization, A.F. and G.R.; methodology, A.F. and G.R.; validation, A.F. and G.R.; formal analysis, A.F.; investigation, A.F.; resources, A.F.; data curation, A.F. and G.R.; writing-original draft preparation, A.F.; writing-review and editing, A.F., G.R.; visualization, A.F.; supervision, G.R. All authors have read and agreed to the published version of the manuscript.

Funding: This research received no external funding.

Acknowledgments: Part of this work has been carried out within the scope of the project Power Semiconductor and Electronics Manufacturing 4.0 - (Semi40), under grant agreement No 962466. The project is co-funded by grants from Austria, Germany, Italy, France, Portugal and the Electronic Component Systems for European Leadership Joint Undertaking (ECSEL JU).

Conflicts of Interest: The authors declare no conflict of interest.

\section{Appendix A}

Table A1. Authors, sustainability dimension and P\&OM areas.

\begin{tabular}{|c|c|c|c|c|c|c|}
\hline Nr. & Author & EcEvS & EcEv & EcS & EvS & P\&OM Area \\
\hline 1 & Ahmad et al. (2020) & $x$ & & & & Manufacturing \\
\hline 2 & Alreshidi (2019) & & $x$ & & & Supply Chain \\
\hline 3 & Ardanza et al. (2019) & & & $X$ & & Manufacturing \\
\hline 4 & Arnal et al. (2020) & & $X$ & & & Manufacturing \\
\hline 5 & Azizi (2020) & & $X$ & & & Manufacturing \\
\hline 6 & Banyai et al. (2019) & & $X$ & & & Supply Chain \\
\hline 7 & Batkovskiy et al. (2019) & & & $x$ & & Manufacturing \\
\hline 8 & Bechtsis et al. (2017) & $x$ & & & & Supply Chain \\
\hline 9 & Beier et al. (2020) & $x$ & & & & Manufacturing \\
\hline 10 & Birkel et al. (2019) & $x$ & & & & Manufacturing \\
\hline 11 & Bonilla et al. (2018) & & & & $x$ & Manufacturing \\
\hline 12 & Braccini; Margherita (2019) & $x$ & & & & Manufacturing \\
\hline 13 & Brozzi et al. (2020) & $x$ & & & & Manufacturing \\
\hline 14 & Chen (2015) & & $x$ & & & Supply Chain \\
\hline 15 & Chen et al. (2018) & & $X$ & & & Manufacturing \\
\hline 16 & Chiarini et al. (2020) & & $x$ & & & Supply Chain \\
\hline 17 & Culot et al. (2020) & $x$ & & & & Manufacturing \\
\hline 18 & Delgosha et al. (2020) & $x$ & & & & Manufacturing \\
\hline 19 & Dev et al. (2020) & $x$ & & & & Supply Chain \\
\hline 20 & Ding (2018) & $x$ & & & & Supply Chain \\
\hline 21 & El Hilali et al. (2020) & $x$ & & & & Manufacturing \\
\hline 22 & Fatorachian; Kazemi (2020) & & $x$ & & & Supply Chain \\
\hline 23 & Forcadell et al. (2020) & & & $X$ & & Service \\
\hline 24 & Gabriel; Pessl (2016) & & & & $X$ & Manufacturing \\
\hline 25 & Garcia-Muina et al. (2020) & $x$ & & & & Manufacturing \\
\hline 26 & Garrido-Hidalgo et al. (2018) & & & & $x$ & Manufacturing \\
\hline 27 & Ghadimi et al. (2019) & $X$ & & & & Supply Chain \\
\hline 28 & Ghobakhloo (2018) & & & $x$ & & Manufacturing \\
\hline 29 & Ghobakhloo (2019) & $\mathrm{X}$ & & & & Manufacturing \\
\hline
\end{tabular}


Table A1. Cont.

\begin{tabular}{|c|c|c|c|c|c|c|}
\hline Nr. & Author & EcEvS & EcEv & EcS & EvS & P\&OM Area \\
\hline 30 & Ghobakhloo; Fathi (2019) & $x$ & & & & Manufacturing \\
\hline 31 & Herrmann et al. (2014) & $x$ & & & & Manufacturing \\
\hline 32 & Hetemi et al. (2020) & & & $x$ & & Service \\
\hline 33 & Ivascu (2020) & $X$ & & & & Manufacturing \\
\hline 34 & Jabbour et al. (2018) & & $x$ & & & Manufacturing \\
\hline 35 & Jardim-Goncalves et al. (2017) & & & & $x$ & Manufacturing \\
\hline 36 & Jena et al. (2020) & & $x$ & & & Manufacturing \\
\hline 37 & Johansson et al. (2019) & $x$ & & & & Manufacturing \\
\hline 38 & Joo et al. (2017) & & $x$ & & & Manufacturing \\
\hline 39 & Junge (2019) & $x$ & & & & Supply Chain \\
\hline 40 & Kamble et al. (2018) & $x$ & & & & Manufacturing \\
\hline 41 & Kamble et al. (2018) & $x$ & & & & Manufacturing \\
\hline 42 & Kamble et al. (2020) & $x$ & & & & Manufacturing \\
\hline 43 & Kao et al. (2019) & & & $x$ & & Manufacturing \\
\hline 44 & Kiel et al. (2017) & $x$ & & & & Manufacturing \\
\hline 45 & Kumar et al. (2018) & & $X$ & & & Manufacturing \\
\hline 46 & Larsen et al. (2019) & $x$ & & & & Supply Chain \\
\hline 47 & Lin $(2018)$ & $x$ & & & & Manufacturing \\
\hline 48 & Lin et al. (2017) & $x$ & & & & Manufacturing \\
\hline 49 & Liu; Giovanni (2019) & & $x$ & & & Supply Chain \\
\hline 50 & Lopes de Sousa et al. (2018) & $x$ & & & & Supply Chain \\
\hline 51 & Luthra et al. (2020) & $x$ & & & & Supply Chain \\
\hline 52 & Luthra; Mangla (2018) & $x$ & & & & Supply Chain \\
\hline 53 & MacCarthy et al. (2016) & & $x$ & & & Supply Chain \\
\hline 54 & Machado et al. (2020) & $x$ & & & & Manufacturing \\
\hline 55 & Malik et al. (2017) & & & & $x$ & Manufacturing \\
\hline 56 & Mattos Nascimento et al. (2019) & $x$ & & & & Manufacturing \\
\hline 57 & Micieta et al. (2019) & & & $x$ & & Manufacturing \\
\hline 58 & Mueller et al. (2018) & $x$ & & & & Manufacturing \\
\hline 59 & Mueller; Voigt (2018) & $x$ & & & & Manufacturing \\
\hline 60 & Nagy et al. (2018) & & & $x$ & & Supply Chain \\
\hline 61 & Ordieres-Mere et al. (2020) & $x$ & & & & Supply Chain \\
\hline 62 & Pashkevich et al. (2019) & & $X$ & & & Manufacturing \\
\hline 63 & Prause (2015) & & $x$ & & & Manufacturing \\
\hline 64 & Prause; Atari (2017) & & & $x$ & & Manufacturing \\
\hline 65 & Pyka (2017) & & & $x$ & & Service \\
\hline 66 & Ramirez-Pena et al. (2020) & $x$ & & & & Supply Chain \\
\hline 67 & Rane; Thakker (2019) & & $x$ & & & Supply Chain \\
\hline 68 & Salah et al. (2019) & & & $x$ & & Service \\
\hline 69 & Scavarda et al. (2019) & $x$ & & & & Manufacturing \\
\hline 70 & Seo et al. (2018) & & $x$ & & & Manufacturing \\
\hline 71 & Serban (2017) & $x$ & & & & Manufacturing \\
\hline 72 & Shahzad et al. (2020) & & $x$ & & & Manufacturing \\
\hline 73 & Shamshiri et al. (2020) & & $x$ & & & Supply Chain \\
\hline 74 & Stergiou et al. (2018) & $x$ & & & & Manufacturing \\
\hline 75 & Stock et al. (2018) & & & & $x$ & Supply Chain \\
\hline 76 & Stock; Seliger (2016) & $x$ & & & & Manufacturing \\
\hline 77 & Tirabeni et al. (2019) & $x$ & & & & Manufacturing \\
\hline 78 & Tiwari; Khan (2020) & $x$ & & & & Manufacturing \\
\hline 79 & Tsai (2018) & $x$ & & & & Manufacturing \\
\hline 80 & Tsai; Lai (2018) & $x$ & & & & Manufacturing \\
\hline 81 & Tsai; Lu (2018) & $x$ & & & & Manufacturing \\
\hline 82 & Varela et al. (2019) & $x$ & & & & Manufacturing \\
\hline 83 & Wang et al. (2016) & & $X$ & & & Manufacturing \\
\hline 84 & Wang et al. (2018) & & $x$ & & & Manufacturing \\
\hline 85 & Yadav et al. (2020) & $x$ & & & & Supply Chain \\
\hline 86 & Yazdi et al. (2018) & & $x$ & & & Manufacturing \\
\hline 87 & Zhao et al. (2019) & & & $x$ & & Manufacturing \\
\hline 88 & Zhao et al. (2020) & & & & $x$ & Manufacturing \\
\hline 89 & Zheng et al. (2019) & $x$ & & & & Manufacturing \\
\hline
\end{tabular}




\section{Appendix B}

Table A2. Focus group discussion results (Group A).

\begin{tabular}{|c|c|c|c|c|c|}
\hline Focus Group & Q1 & Q2 & Q3 & $\mathrm{Q} 4$ & Q5 \\
\hline A & $\begin{array}{l}\text { A Smart and flexible } \\
\text { production environment with } \\
\text { components interacting } \\
\text { dynamically (humans, } \\
\text { material, machines) } \\
\text { Intelligent networks, linkage } \\
\text { of human to machine and } \\
\text { technological environment }\end{array}$ & $\begin{array}{c}\text { Strategic level } \\
\text { Definition of policies for } \\
\text { dynamic systems } \\
\text { Flatten organizational } \\
\text { hierarchies } \\
\text { New management roles } \\
\text { Increase of educational } \\
\text { measures } \\
\text { Tactical level } \\
\text { Safe and protected } \\
\text { manufacturing environments } \\
\text { Better error handling } \\
\text { Operational level } \\
\text { Better process monitoring } \\
\text { Cycle time optimization } \\
\text { Employees will have } \\
\text { more responsibilities }\end{array}$ & $\begin{array}{c}\text { Economic } \\
\text { Return on investment (ROI) } \\
\text { Cycle time } \\
\text { System Availability } \\
\text { System reliability } \\
\text { Expandability of technology } \\
\text { Quality measures } \\
\text { Number of returns } \\
\text { Environmental } \\
\text { Energy efficiency } \\
\text { Waste reduction } \\
\mathrm{CO}_{2} \text { emission } \\
\text { Social } \\
\text { Relation of high vs. low } \\
\text { qualification jobs } \\
\text { Employee satisfaction } \\
\text { Change of work behavior } \\
\text { Employee fluctuation } \\
\text { Level of education. }\end{array}$ & $\begin{array}{c}\text { Economic } \\
\text { Flexibility measures } \\
\text { Internal maturity level } \\
\text { Activity based costing key } \\
\text { performance indicators (KPIs) } \\
\text { Implementation Costs vs. Benefit } \\
\text { Environmental } \\
\text { Smart meters } \\
\text { Energy efficient layout structures } \\
\text { Social } \\
\text { Control frequency and work load } \\
\text { Measurement of new job profiles } \\
\text { Stress level } \\
\text { Efficiency of employees } \\
\text { New skills } \\
\text { Influence level of IoT } \\
\text { on employee } \\
\text { Employee satisfaction }\end{array}$ & $\begin{array}{c}\text { Economic } \\
\text { New projects and concepts } \\
\text { New technologies ensure } \\
\text { profitability } \\
\text { Company growth } \\
\text { New company structures } \\
\text { Higher level of innovation } \\
\text { Competitiveness } \\
\text { Increase of company } \\
\text { networks } \\
\text { Reinforced EU networks. } \\
\text { Environmental } \\
\text { Energy efficiency } \\
\text { Social } \\
\text { More attractive student } \\
\text { programs } \\
\text { Better education programs } \\
\text { Increase of } \\
\text { technical education }\end{array}$ \\
\hline
\end{tabular}


Table A3. Focus group discussion results (Group B).

\begin{tabular}{|c|c|c|c|c|c|}
\hline Focus Group & Q1 & Q2 & Q3 & Q4 & Q5 \\
\hline B & $\begin{array}{c}\text { Standardization procedures } \\
\text { by large organizations such as } \\
\text { Platform I4.0, Zentralverband } \\
\text { Elektrotechnik- und } \\
\text { Eelektronikindustrie (ZVEI), } \\
\text { Verein Deutscher Ingenieure } \\
\text { (VDI). They define } \\
\text { specifications like Reference } \\
\text { Architectural Model Industrie } \\
4.0 \text { (RAMI4.0), Structure of } \\
\text { I4.0 secure identities }\end{array}$ & $\begin{array}{c}\text { Strategic level } \\
\text { Prevention of cyber crime } \\
\text { Flatten hierarchy } \\
\text { New job profiles } \\
\text { Change of organizational } \\
\text { structure. } \\
\text { Tactical level } \\
\text { Secure communication of } \\
\text { industrial pilots } \\
\text { Increase of multidisciplinarity } \\
\text { Operational level } \\
\text { Secure communication of } \\
\text { industrial production } \\
\text { components } \\
\text { Secure M2M communication } \\
\text { Authorized interaction of } \\
\text { humans into } \\
\text { production process }\end{array}$ & $\begin{array}{c}\text { Economic } \\
\text { Compare pre and } \\
\text { post situation } \\
\text { Traceability in the value chain } \\
\text { Quality KPIs } \\
\text { Cycle times } \\
\text { Environmental } \\
\text { Energy efficiency } \\
\text { Social } \\
\text { Fluctuation of employees } \\
\text { Satisfaction of employees } \\
\text { Number of new jobs } \\
\text { New team structures }\end{array}$ & $\begin{array}{c}\text { Economic } \\
\text { Personnel costs } \\
\text { Profit, sales due to I4.0 } \\
\text { Environmental } \\
\text { Flexibility in production } \\
\text { New ROI measures } \\
\text { Environmental } \\
\text { Impact of robotics on reduction of } \\
\text { hazardous accidents } \\
\text { Social } \\
\text { The possibility to separate the } \\
\text { social impact from } \\
\text { other influences } \\
\text { Reduction of human involvement } \\
\text { Learning speed } \\
\text { How many jobs created } \\
\text { through'I4.0 }\end{array}$ & $\begin{array}{c}\text { Economic } \\
\text { Our company can acquire } \\
\text { projects for creation of I4.0 } \\
\text { components } \\
\text { Increase of workplace safety } \\
\text { and IT-security } \\
\text { Environmental } \\
\text { Waste reduction } \\
\text { Social } \\
\text { New job systems } \\
\text { Better knowledge } \\
\text { management } \\
\text { New processes will change } \\
\text { work behavior } \\
\text { More risks such as: burn out } \\
\text { rate; new challenges } \\
\text { for society } \\
\text { Less operations } \\
\text { Experience is too low } \\
\text { Reduction of specific } \\
\text { job functions }\end{array}$ \\
\hline
\end{tabular}


Table A4. Focus group discussion results (Group C).

\begin{tabular}{|c|c|c|c|c|c|}
\hline Focus Group & Q1 & Q2 & Q3 & Q4 & Q5 \\
\hline $\mathrm{C}$ & $\begin{array}{c}\text { Automation of } \\
\text { industrial processes. } \\
\text { Enhanced decision support; } \\
\text { defines the application of } \\
\text { smart sustainable } \\
\text { technologies. } \\
\text { Combination of emerging IT } \\
\text { technologies; CPPS; robots, } \\
\text { Information and } \\
\text { communications } \\
\text { technology (ICT). } \\
\text { Networking (analog } \\
\text { to automation) } \\
\text { Integration of machine to } \\
\text { human communication. }\end{array}$ & $\begin{array}{c}\text { Strategic level } \\
\text { Increase of company } \\
\text { awareness and transparency } \\
\text { Reduction of CO2 emissions, } \\
\text { due to more efficient } \\
\text { production systems and } \\
\text { supply chains. } \\
\text { Companies should generate } \\
\text { acceptance for new } \\
\text { in-house areas } \\
\text { Tactical Level } \\
\text { Knowledge management } \\
\text { Operational level } \\
\text { New Job functions, impact on } \\
\text { social skills, Influence of new } \\
\text { technology on work behavior } \\
\text { Use of assistance systems }\end{array}$ & $\begin{array}{c}\text { Economic } \\
\text { Customer satisfaction } \\
\text { Flexibility, Overall Equipment } \\
\text { Effectiveness (OEE) } \\
\text { Scrap rate } \\
\text { Time to market } \\
\text { Cycle time } \\
\text { Throughput rate } \\
\text { Environmental } \\
\text { Resource efficiency } \\
\text { Social } \\
\text { Global Reporting Index } \\
\text { Shift of qualification } \\
\text { Number of staff ill } \\
\text { Distribution of employees } \\
\text { Balanced workload }\end{array}$ & $\begin{array}{c}\text { Economic } \\
\text { Measurement for } \\
\text { non-tangible effects? } \\
\text { Requests of companies } \\
\text { to government } \\
\text { System flexibility } \\
\text { Environmental } \\
\text { Smart meters for fab layouts } \\
\text { Data lake and resource efficiency } \\
\text { Social } \\
\text { Measures for Technical impact on } \\
\text { social environment }\end{array}$ & $\begin{array}{c}\text { Economic } \\
\text { Increase of transparency } \\
\text { Faster and more reliable } \\
\text { production processes } \\
\text { Improved process quality } \\
\text { Increase of } \\
\text { production volume } \\
\text { Increase of cyber attacks } \\
\text { Environmental } \\
\text { Resource efficient ecosystems } \\
\text { Social } \\
\text { Increase of knowledge } \\
\text { management, } \\
\text { Increase of expert knowledge } \\
\text { Knowledge of days past } \\
\text { could be lost } \\
\text { New processes will change } \\
\text { work behavior } \\
\text { Different communication } \\
\text { between employees }\end{array}$ \\
\hline
\end{tabular}


Table A5. Focus group discussion results (Group D).

\begin{tabular}{|c|c|c|c|c|c|}
\hline Focus Group & Q1 & Q2 & Q3 & Q4 & Q5 \\
\hline $\mathrm{D}$ & $\begin{array}{c}\text { Integration of new } \\
\text { technologies (IoT, smart } \\
\text { Web2.0) in Industry. } \\
\text { Automated, enhanced } \\
\text { decision support based on } \\
\text { digitized data } \\
\text { collection/interaction, } \\
\text { Integrated communication; all } \\
\text { areas are affected } \\
\text { management and production } \\
\text { I4.0 support employees in } \\
\text { production processes } \\
\text { (maintenance) } \\
\text { Linkage of human to machine } \\
\text { and technology } \\
\text { Intelligent I4.0 value chain } \\
\text { networks influencing overall } \\
\text { sustainability of ecosystems }\end{array}$ & $\begin{array}{c}\text { Strategic level } \\
\text { Cycle time optimization } \\
\text { Organization structures will } \\
\text { change (flatten hierarchy) } \\
\text { New I4.0 alliances } \\
\text { between organizations } \\
\text { Tactical level } \\
\text { People will have a bigger area } \\
\text { of responsibility } \\
\text { Operational level } \\
\text { Employees need a better } \\
\text { overview of the } \\
\text { production processes } \\
\text { System knowledge } \\
\text { will increase } \\
\text { New roles and job profiles } \\
\text { will arise } \\
\text { Employees will work within } \\
\text { the whole system, no longer } \\
\text { separated in departments }\end{array}$ & $\begin{array}{c}\text { Economic } \\
\text { Unit costs } \\
\text { Expanded system functions } \\
\text { Market share } \\
\text { Maintenance costs } \\
\text { Set-up times } \\
\text { Discard rate } \\
\text { Environmental } \\
\text { Reduction of emissions } \\
\text { Social } \\
\text { Employee fluctuation } \\
\text { Education level } \\
\text { Cross-linked thinking } \\
\text { Change of work behavior }\end{array}$ & $\begin{array}{c}\text { Economic } \\
\text { IoT influence level } \\
\text { Complexity of processes } \\
\text { Increase of flexibility } \\
\text { Environmental } \\
\text { Impact on circularity } \\
\text { Social } \\
\text { Stress level measure } \\
\text { Employee satisfaction } \\
\text { Employee efficiency }\end{array}$ & $\begin{array}{c}\text { Economic } \\
\text { New department structures } \\
\text { Increase of } \\
\text { production flexibility } \\
\text { Decrease of downtimes } \\
\text { Environmental } \\
\text { New Start-ups/spinoffs } \\
\text { Decrease of emissions } \\
\text { Circular economy will benefit } \\
\text { Social } \\
\text { Employees need to combine } \\
\text { theoretical and } \\
\text { practical thinking } \\
\text { New forms of jobs } \\
\text { Contract worker } \\
\text { Affiliation of working } \\
\text { time/leisure time } \\
\text { New job systems } \\
\text { Flexible working hours }\end{array}$ \\
\hline
\end{tabular}


Table A6. Focus group discussion results (Group E).

\begin{tabular}{|c|c|c|c|c|c|}
\hline Focus Group & Q1 & Q2 & Q3 & Q4 & Q5 \\
\hline E & $\begin{array}{l}\text { Defines the application of } \\
\text { smart, innovative } \\
\text { technologies for automation } \\
\text { of industrial process and the } \\
\text { support of employees in their } \\
\text { work as well as in their } \\
\text { interaction with machines } \\
\text { and processes. } \\
\text { Network embedded systems } \\
\text { for sustainable industrial } \\
\text { revolution and intelligent } \\
\text { integration of } \\
\text { human-machine } \\
\text { Integrated and advanced } \\
\text { automated It-technologies } \\
\text { which aims to set up patency } \\
\text { from sensor until } \\
\text { management and from } \\
\text { components to production } \\
\text { and cross-linked } \\
\text { automation technologies. } \\
\text { Customized and automated } \\
\text { and resource } \\
\text { efficient production }\end{array}$ & $\begin{array}{c}\text { Tactical level } \\
\text { Better system } \\
\text { error prevention } \\
\text { Better logistics } \\
\text { Operational level } \\
\text { Increase of productivity } \\
\text { Production processes involve } \\
\text { both, machines } \\
\text { and employees } \\
\text { Influence of new technologies } \\
\text { on working behavior } \\
\text { Error detection on earlier } \\
\text { production stages } \\
\text { Production and maintenance } \\
\text { Impact on shop } \\
\text { floor personnel }\end{array}$ & $\begin{array}{c}\text { Economic } \\
\text { Productivity } \\
\text { Yield } \\
\text { Speed } \\
\text { Sales } \\
\text { Number of new start ups } \\
\text { Investment costs } \\
\text { Employee costs } \\
\text { Environmental } \\
\text { Reduction of energy } \\
\text { consumption } \\
\text { Reduction of fuel } \\
\text { consumption } \\
\text { Social } \\
\text { Number of ill staff } \\
\text { Comparison of old and } \\
\text { new jobs } \\
\text { Knowledge management } \\
\text { Social skills }\end{array}$ & $\begin{array}{c}\text { Economic } \\
\text { Measure the complexity degree of } \\
\text { production processes } \\
\text { Increase or decrease of costs } \\
\text { Expandability of I4.0 } \\
\text { ROI of green supply chain } \\
\text { Environmental } \\
\text { No comment } \\
\text { Social } \\
\text { IoT influence factor } \\
\text { Employee satisfaction } \\
\text { Number of people lost jobs } \\
\text { Degree of human } \\
\text { machine interaction } \\
\text { Number of new } \\
\text { communications tools } \\
\text { In general more academic } \\
\text { methods should be used }\end{array}$ & $\begin{array}{c}\text { Economic } \\
\text { More valuable knowledge for } \\
\text { the company } \\
\text { Knowledge management } \\
\text { I4.0 will safeguard the } \\
\text { locations long-term and } \\
\text { create a balanced } \\
\text { development perspective } \\
\text { Competitiveness against } \\
\text { of Asia } \\
\text { Environmental } \\
\text { Resource efficiency } \\
\text { Green supply chains } \\
\text { Social } \\
\text { Knowledge management will } \\
\text { get more important } \\
\text { Experts will concentrate on } \\
\text { special topics } \\
\text { In production and offices } \\
\text { machines are getting more } \\
\text { and more intelligent, they will } \\
\text { replace humans } \\
\text { Change of communication }\end{array}$ \\
\hline
\end{tabular}




\section{References}

1. Hannola, L.; Richter, A.; Richter, S.; Stocker, A. Empowering production workers with digitally facilitated knowledge processes-A conceptual framework. Int. J. Prod. Res. 2018, 56, 4729-4743. [CrossRef]

2. Richter, A.; Heinrich, P.; Stocker, A.; Schwabe, G. Digital work design. Bus. Inf. Syst. Eng. 2018, 60, $259-264$. [CrossRef]

3. Marre, M.; Beihofer, D.; Haggenmueller, W.A.; Grupp, P. Forming for Resource-Efficient Industry 4.0. In Proceedings of the 5th International Conference on Accuracy in Forming Technology (ICAFT), Chemnitz, Germany, 10-11 November 2015; pp. 655-673.

4. Penrose, E. The Theory of the Growth of the Firm, 4th ed.; Oxford University Press: Oxford, UK, 2009.

5. Barney, J. Firm resources and sustained competitive advantage. J. Manag. 1991, 17, 99-120. [CrossRef]

6. Melville, N.; Kraemer, K.; Gurbaxani, V. Information technology and organizational performance: An integrative model of IT business value. MIS Q. 2004, 28, 283-322. [CrossRef]

7. Birkel, H.S.; Veile, J.W.; Müller, J.M.; Hartmann, E.; Voigt, K.-I. Development of a risk framework for Industry 4.0 in the context of sustainability for established manufacturers. Sustainability 2019, 11, 384. [CrossRef]

8. Wernerfelt, B. A resource-based view of the firm. Strateg. Manag. J. 1984, 5, 171-180. [CrossRef]

9. Kamble, S.; Gunasekaran, A.; Dhone, N.C. Industry 4.0 and lean manufacturing practices for sustainable organisational performance in Indian manufacturing companies. Int. J. Prod. Res. 2020, 58, 1319-1337. [CrossRef]

10. Kagermann, H. Change through digitization-Value creation in the age of Industry 4.0. In Management of Permanent Change; Albach, H., Meffert, H., Pinkwart, A., Reichwald, R., Eds.; Springer Gabler: Wiesbaden, Germany, 2015; pp. 23-45.

11. Mukherjee, A.; Mitchell, W.; Talbot, F.B. The impact of new manufacturing technologies and strategically flexible production. J. Oper. Manag. 2000, 18, 139-168. [CrossRef]

12. D'heur, M. Shared. Value. Chain: Profitable growth through sustainable value creation. In Sustainable Value Chain Managment; Springer: Cham, Switzerland, 2015; pp. 1-107.

13. Sjödin, D.R.; Parida, V.; Leksell, M.; Petrovic, A. Smart factory implementation and process innovation: A preliminary maturity model for leveraging digitalization in manufacturing moving to smart factories presents specific challenges that can be addressed through a structured approach focused on people, processes, and technologies. Res. Technol. Manag. 2018, 61, 22-31. [CrossRef]

14. Elkington, J. Partnerships from cannibals with forks: The triple bottom line of 21st-century business. Environ. Qual. Manag. 1998, 8, 37-51. [CrossRef]

15. Seuring, S.; Müller, M. From a literature review to a conceptual framework for sustainable supply chain management. J. Clean. Prod. 2008, 16, 1699-1710. [CrossRef]

16. Kagermann, H.; Lukas, W.-D.; Wahlster, W. Industrie 4.0: Mit dem Internet der Dinge auf dem Weg zur 4. industriellen Revolution. VDI Nachr. 2011, 13,1-2.

17. Hermann, M.; Pentek, T.; Otto, B. Design Principles For Industrie 4.0 Scenarios. In Proceedings of the 49th Hawaii International Conference on System Sciences (HICSS), Koloa, HI, USA, 5-8 January 2016; pp. 3928-3937.

18. Spath, D.; Ganschar, O.; Gerlach, S.; Hämmerle, M.; Krause, T.; Schlund, S. Produktionsarbeit der ZukunftIndustrie 4.0; Fraunhofer Verlag: Stuttgart, Germany, 2013.

19. Tortorella, G.L.; Fettermann, D. Implementation of Industry 4.0 and lean production in Brazilian manufacturing companies. Int. J. Prod. Res. 2018, 56, 2975-2987. [CrossRef]

20. Fatorachian, H.; Kazemi, H. A critical investigation of Industry 4.0 in manufacturing: Theoretical operationalisation framework. Prod. Plan. Control. 2018, 29, 633-644. [CrossRef]

21. Fatorachian, H.; Kazemi, H. Impact of Industry 4.0 on supply chain performance. Prod. Plan. Control 2020, 1-19. [CrossRef]

22. Sisinni, E.; Saifullah, A.; Han, S.; Jennehag, U.; Gidlund, M. Industrial internet of things: Challenges, opportunities, and directions. IEEE Trans. Ind. Inform. 2018, 14, 4724-4734. [CrossRef]

23. Moeuf, A.; Pellerin, R.; Lamouri, S.; Tamayo-Giraldo, S.; Barbaray, R. The industrial management of SMEs in the era of Industry 4.0. Int. J. Prod. Res. 2018, 56, 1118-1136. [CrossRef] 
24. Strozzi, F.; Colicchia, C.; Creazza, A.; Noè, C. Literature review on the 'Smart Factory'concept using bibliometric tools. Int. J. Prod. Res. 2017, 55, 6572-6591. [CrossRef]

25. Kusiak, A. Smart manufacturing. Int. J. Prod. Res. 2018, 56, 508-517. [CrossRef]

26. Beier, G.; Niehoff, S.; Xue, B. More sustainability in industry through industrial internet of things? Appl. Sci. 2018, 8, 219. [CrossRef]

27. Galati, F.; Bigliardi, B. Industry 4.0: Emerging themes and future research avenues using a text mining approach. Comput. Ind. 2019, 109, 100-113. [CrossRef]

28. De Man, J.C.; Strandhagen, J.O. An Industry 4.0 research agenda for sustainable business models. Procedia CIRP 2017, 63, 721-726. [CrossRef]

29. Bonilla, S.H.; Silva, H.R.O.; da Silva, M.T.; Franco Gonçalves, R.; Sacomano, J.B. Industry 4.0 and sustainability implications: A scenario-based analysis of the impacts and challenges. Sustainability 2018, 10, 3740. [CrossRef]

30. Ghobakhloo, M. Industry 4.0, digitization, and opportunities for sustainability. J. Clean. Prod. 2020, 252, 119869. [CrossRef]

31. Seebacher, G. Ansätze zur Beurteilung der Produktionswirtschaftlichen Flexibilität; Logos Verlag Berlin GmbH: Berlin, Germany, 2013; pp. 20-120.

32. Cagliano, R.; Spina, G. Advanced manufacturing technologies and strategically flexible production. J. Oper. Manag. 2000, 18, 169-190. [CrossRef]

33. Ciffolilli, A.; Muscio, A. Industry 4.0: National and regional comparative advantages in key enabling technologies. Eur. Plan. Stud. 2018, 26, 2323-2343. [CrossRef]

34. Ben-Daya, M.; Hassini, E.; Bahroun, Z. Internet of things and supply chain management: A literature review. Int. J. Prod. Res. 2019, 57, 4719-4742. [CrossRef]

35. Felsberger, A.; Qaiser, F.; Choudhary, A.; Reiner, G. The impact of Industry 4.0 on the reconciliation of dynamic capabilities: Evidence from the European manufacturing industries. Prod. Plan. Control 2020. [CrossRef]

36. Lasi, H.; Fettke, P.; Kemper, H.-G.; Feld, T.; Hoffmann, M. Industry 4.0. Bus. Inf. Syst. Eng. 2014, 6, $239-242$. [CrossRef]

37. Zhong, R.Y.; Xu, X.; Klotz, E.; Newman, S.T. Intelligent manufacturing in the context of industry 4.0: A review. Engineering 2017, 3, 616-630. [CrossRef]

38. Petticrew, M.; Roberts, H. Systematic Reviews in the Social Sciences: A Practical Guide; John Wiley \& Sons: Oxford, UK, 2006.

39. Fink, A. Conducting Research Literature Reviews: From the Internet to Paper, 5th ed.; Sage Publications: Thousand Oaks, CA, USA, 2020.

40. Kunz, N.; Reiner, G. A meta-analysis of humanitarian logistics research. J. Humanit. Logist. Supply Chain Manag. 2012. [CrossRef]

41. Wankmüller, C.; Reiner, G. Coordination, cooperation and collaboration in relief supply chain management. J. Bus. Econ. 2020, 90, 239-276. [CrossRef]

42. Meredith, J. Theory building through conceptual methods. Int. J. Oper. Prod. Manag. 1993, 13, 3-11. [CrossRef]

43. Powell, R.A.; Single, H.M. Focus groups. Int. J. Qual. Health Care 1996, 8, 499-504. [CrossRef]

44. Fern, E.F. Methodological issues in focus group research: Representativeness, independence, degrees of freedom, and theory confirmation. Adv. Focus Group Res. 2001, 121-148. [CrossRef]

45. Xiao, Y.; Watson, M. Guidance on conducting a systematic literature review. J. Plan. Educ. Res. 2019, 39, 93-112. [CrossRef]

46. Gopalakrishnan, S.; Ganeshkumar, P. Systematic reviews and meta-analysis: Understanding the best evidence in primary healthcare. J. Fam. Med. Prim. Care 2013, 2, 9-14. [CrossRef]

47. Mallett, R.; Hagen-Zanker, J.; Slater, R.; Duvendack, M. The benefits and challenges of using systematic reviews in international development research. J. Dev. Eff. 2012, 4, 445-455. [CrossRef]

48. Morgan, D.L. Focus groups. Annu. Rev. Sociol. 1996, 22, 129-152. [CrossRef]

49. Berry, K.; Kincheloe, J. Rigour and Complexity in Educational Research. Conducting Educational Research; Open University Press: Columbus, OH, USA, 2004.

50. Litosseliti, L. Using Focus Groups in Research; Continuum: London, UK, 2003; pp. 30-80. 
51. Mukherjee, N.; Huge, J.; Sutherland, W.J.; McNeill, J.; van Opstal, M.; Dahdouh-Guebas, F.; Koedam, N. The Delphi technique in ecology and biological conservation: Applications and guidelines. Methods Ecol. Evol. 2015, 6, 1097-1109. [CrossRef]

52. Nyumba, T.; Wilson, K.; Derrick, C.J.; Mukherjee, N. The use of focus group discussion methodology: Insights from two decades of application in conservation. Methods Ecol. Evol. 2018, 9, 20-32. [CrossRef]

53. Wilding, R.; Wagner, B.; Colicchia, C.; Strozzi, F. Supply chain risk management: A new methodology for a systematic literature review. Supply Chain Manag. Int. J. 2012. [CrossRef]

54. Chadegani, A.A.; Salehi, H.; Yunus, M.; Farhadi, H.; Fooladi, M.; Farhadi, M.; Ale Ebrahim, N. A comparison between two main academic literature collections: Web of Science and Scopus databases. Asian Soc. Sci. 2013, 9, 18-26. [CrossRef]

55. Jahangirian, M.; Eldabi, T.; Naseer, A.; Stergioulas, L.K.; Young, T. Simulation in manufacturing and business: A review. Eur. J. Oper. Res. 2010, 203, 1-13. [CrossRef]

56. Jena, M.C.; Mishra, S.K.; Moharana, H.S. Application of Industry 4.0 to enhance sustainable manufacturing. Environ. Prog. Sustain. Energy 2020, 39, 13360. [CrossRef]

57. Herrmann, C.; Schmidt, C.; Kurle, D.; Blume, S.; Thiede, S. Sustainability in manufacturing and factories of the future. Int. J. Precis. Eng. Manuf. Green Technol. 2014, 1, 283-292. [CrossRef]

58. Bechtsis, D.; Tsolakis, N.; Vlachos, D.; Iakovou, E. Sustainable supply chain management in the digitalisation era: The impact of automated guided vehicles. J. Clean. Prod. 2017, 142, 3970-3984. [CrossRef]

59. Kumar, R.; Singh, S.P.; Lamba, K. Sustainable robust layout using Big Data approach: A key towards industry 4.0. J. Clean. Prod. 2018, 204, 643-659. [CrossRef]

60. Tiwari, K.; Khan, M.S. Sustainability accounting and reporting in the Industry 4.0. J. Clean. Prod. 2020, 120783. [CrossRef]

61. Yadav, G.; Luthra, S.; Jakhar, S.K.; Mangla, S.K.; Rai, D.P. A framework to overcome sustainable supply chain challenges through solution measures of industry 4.0 and circular economy: An automotive case. J. Clean. Prod. 2020, 254, 120112. [CrossRef]

62. Jabbour, A.B.L.D.S.; Jabbour, C.J.C.; Filho, M.G.; Roubaud, D. Industry 4.0 and the circular economy: A proposed research agenda and original roadmap for sustainable operations. Ann. Oper. Res. 2018, 270, 273-286. [CrossRef]

63. Müller, J.M.; Voigt, K.-I. Sustainable industrial value creation in SMEs: A comparison between industry 4.0 and made in China 2025. Int. J. Precis. Eng. Manuf. Green Technol. 2018, 5, 659-670. [CrossRef]

64. Kamble, S.; Gunasekaran, A.; Gawankar, S.A. Sustainable Industry 4.0 framework: A systematic literature review identifying the current trends and future perspectives. Process Saf. Environ. Prot. 2018, 117, 408-425. [CrossRef]

65. European Commission. Horizon 2020: Work Programme 2018-2020. Available online: https://ec.europa.eu/ commission/presscorner/detail/en/MEMO_17_4123 (accessed on 12 August 2020).

66. Tian, S.; Pan, Z. “Made in China 2025 "und" Industrie 4.0”-Gemeinsam in Bewegung. In Industrie 4.0 Grenzenlos; Sendler, U., Ed.; Springer: Berlin/Heidelberg, Germany, 2016; pp. 91-118. [CrossRef]

67. Rojko, A. Industry 4.0 concept: Background and overview. Int. J. Interact. Mob. Technol. 2017, 11, 77-90. [CrossRef]

68. Jackson, K.; Bazeley, P. Qualitative Data Analysis with NVivo, 3rd ed.; Sage Publications Limited: London, UK, 2019; pp. 9-97.

69. Voss, C.; Tsikriktsis, N.; Frohlich, M. Case research in operations management. Int. J. Oper. Prod. Manag. 2002. [CrossRef]

70. Yin, R.K. Case Study Research: Design and Methods, 4th ed.; Sage Publications: Thousand Oaks, CA, USA, 2009. [CrossRef]

71. Beier, G.; Ullrich, A.; Niehoff, S.; Reißig, M.; Habich, M. Industry 4.0: How it is defined from a sociotechnical perspective and how much sustainability it includes-A literature review. J. Clean. Prod. 2020, 120856. [CrossRef]

72. Forcadell, F.J.; Aracil, E.; Úbeda, F. The impact of corporate sustainability and digitalization on international banks' performance. Glob. Policy 2020, 11, 18-27. [CrossRef] 
73. Junge, A.L. Digital transformation technologies as an enabler for sustainable logistics and supply chain processes-An exploratory framework. Braz. J. Oper. Prod. Manag. 2019, 16, 462-472. [CrossRef]

74. Machado, C.G.; Winroth, M.P.; da Silva, E.H.D.R. Sustainable manufacturing in Industry 4.0: An emerging research agenda. Int. J. Prod. Res. 2020, 58, 1462-1484. [CrossRef]

75. Slack, N.; Lewis, M. Operations Strategy, 2nd ed.; Financial Times/Prentice Hall: Harlow, UK, 2008.

76. Rane, S.B.; Thakker, S.V. Green procurement process model based on blockchain-IoT integrated architecture for a sustainable business. Manag. Environ. Qual. Int. J. 2019. [CrossRef]

77. Dev, N.K.; Shankar, R.; Qaiser, F.H. Industry 4.0 and circular economy: Operational excellence for sustainable reverse supply chain performance. Resour. Conserv. Recycl. 2020, 153, 104583. [CrossRef]

78. Li, L. China's manufacturing locus in 2025: With a comparison of "Made-in-China 2025" and "Industry 4.0". Technol. Forecast. Soc. Chang. 2018, 135, 66-74. [CrossRef]

79. Kavakeb, S.; Nguyen, T.T.; McGinley, K.; Yang, Z.; Jenkinson, I.; Murray, R. Green vehicle technology to enhance the performance of a European port: A simulation model with a cost-benefit approach. Transp. Res. Part C Emerg. Technol. 2015, 60, 169-188. [CrossRef]

80. Shukla, A.; Karki, H. Application of robotics in onshore oil and gas industry-A review Part I. Robot. Auton. Syst. 2016, 75, 490-507. [CrossRef]

81. Acciaro, M.; Wilmsmeier, G. Energy efficiency in maritime logistics chains. Res. Transp. Bus. Manag. 2015, 1-7. [CrossRef]

82. Kiel, D.; Müller, J.M.; Arnold, C.; Voigt, K.-I. Sustainable industrial value creation: Benefits and challenges of industry 4.0. Int. J. Innov. Manag. 2017, 21, 1740015. [CrossRef]

83. Stock, T.; Obenaus, M.; Kunz, S.; Kohl, H. Industry 4.0 as enabler for a sustainable development: A qualitative assessment of its ecological and social potential. Process Saf. Environ. Prot. 2018, 118, 254-267. [CrossRef]

84. Ding, B. Pharma industry 4.0: Literature review and research opportunities in sustainable pharmaceutical supply chains. Process Saf. Environ. Prot. 2018, 119, 115-130. [CrossRef]

85. Varela, L.; Araújo, A.; Ávila, P.; Castro, H.; Putnik, G. Evaluation of the relation between lean manufacturing, Industry 4.0, and sustainability. Sustainability 2019, 11, 1439. [CrossRef]

86. Ahmad, S.; Miskon, S.; Alabdan, R.; Tlili, I. Towards sustainable textile and apparel industry: Exploring the role of business intelligence systems in the era of industry 4.0. Sustainability 2020, 12, 2632. [CrossRef]

87. García-Muiña, F.E.; Medina-Salgado, M.S.; Ferrari, A.; Cucchi, M. Sustainability transition in industry 4.0 and smart manufacturing with the triple-layered business model canvas. Sustainability 2020, 12, 2364. [CrossRef]

88. Johansson, N.; Roth, E.; Reim, W. Smart and sustainable emaintenance: Capabilities for digitalization of maintenance. Sustainability 2019, 11, 3553. [CrossRef]

89. Pereira, A.C.; Romero, F. A review of the meanings and the implications of the Industry 4.0 concept. Procedia Manuf. 2017, 13, 1206-1214. [CrossRef]

90. Nagy, J.; Oláh, J.; Erdei, E.; Máté, D.; Popp, J. The role and impact of Industry 4.0 and the internet of things on the business strategy of the value chain-The case of Hungary. Sustainability 2018, 10, 3491. [CrossRef]

91. Essakly, A.; Wichmann, M.; Spengler, T.S. A reference framework for the holistic evaluation of Industry 4.0 solutions for small-and medium-sized enterprises. IFAC PapersOnLine 2019, 52, 427-432. [CrossRef]

92. Oesterreich, T.D.; Teuteberg, F. Understanding the implications of digitisation and automation in the context of Industry 4.0: A triangulation approach and elements of a research agenda for the construction industry. Comput. Ind. 2016, 83, 121-139. [CrossRef]

93. Brozzi, R.; Forti, D.; Rauch, E.; Matt, D.T. The Advantages of Industry 4.0 Applications for Sustainability: Results from a Sample of Manufacturing Companies. Sustainability 2020, 12, 3647. [CrossRef]

94. Atzori, L.; Iera, A.; Morabito, G. The Internet of Things: A survey. Comput. Netw. 2010, 54, 2787-2805. [CrossRef]

95. Wollschlaeger, M.; Sauter, T.; Jasperneite, J. The future of industrial communication: Automation networks in the era of the internet of things and industry 4.0. IEEE Ind. Electron. Mag. 2017, 11, 17-27. [CrossRef]

96. Liu, Q.; Wan, J.; Zhou, K. Cloud manufacturing service system for industrial-cluster-oriented application. J. Internet Technol. 2014, 15, 373-380. [CrossRef]

97. Radziwon, A.; Bilberg, A.; Bogers, M.; Madsen, E.S. The smart factory: Exploring adaptive and flexible manufacturing solutions. Procedia Eng. 2014, 69, 1184-1190. [CrossRef] 
98. Wan, J.; Zhang, D.; Zhao, S.; Yang, L.T.; Lloret, J. Context-aware vehicular cyber-physical systems with cloud support: Architecture, challenges, and solutions. IEEE Commun. Mag. 2014, 52, 106-113. [CrossRef]

99. Lucke, D.; Constantinescu, C.; Westkämper, E. Smart factory-a step towards the next generation of manufacturing. In Manufacturing Systems and Technologies for the New Frontier; Mitsuishi, M., Ueda, K., Kimura, F., Eds.; Springer: London, UK, 2008; pp. 115-118.

100. Ghobakhloo, M. The future of manufacturing industry: A strategic roadmap toward Industry 4.0. J. Manuf. Technol. Manag. 2018, 910-936. [CrossRef]

101. Stocker, A.; Brandl, P.; Michalczuk, R.; Rosenberger, M. Mensch-zentrierte IKT-Lösungen in einer Smart Factory. e E i Elektrotechnik Inf. 2014, 131, 207-211. [CrossRef]

102. Rüßmann, M.; Lorenz, M.; Gerbert, P.; Waldner, M.; Justus, J.; Engel, P.; Harnisch, M. Industry 4.0: The future of productivity and growth in manufacturing industries. Boston Consult. Group 2015, 9, 54-89.

103. Felsberger, A.; Oberegger, B.; Reiner, G. A Review of Decision Support Systems for Manufacturing Systems. InSAMI@ iKNOW; CEUR-WS: Graz, Austria, 2016.

104. Tsai, W.-H.; Lu, Y.-H. A framework of production planning and control with carbon tax under industry 4.0. Sustainability 2018, 10, 3221. [CrossRef]

105. El Hilali, W.; El Manouar, A.; Idrissi, M.A.J. Reaching sustainability during a digital transformation: A PLS approach. Int. J. Innov. Sci. 2020. [CrossRef]

106. Stergiou, C.; Psannis, K.E.; Gupta, B.B.; Ishibashi, Y. Security, privacy \& efficiency of sustainable cloud computing for big data \& IoT. Sustain. Comput. Inform. Syst. 2018, 19, 174-184. [CrossRef]

107. Culot, G.; Nassimbeni, G.; Orzes, G.; Sartor, M. The future of manufacturing: A Delphi-based scenario analysis on Industry 4.0. Technol. Forecast. Soc. Chang. 2020, 120092. [CrossRef]

108. Garrido-Hidalgo, C.; Hortelano, D.; Roda-Sanchez, L.; Olivares, T.; Ruiz, M.C.; Lopez, V. IoT heterogeneous mesh network deployment for human-in-the-loop challenges towards a social and sustainable Industry 4.0. IEEE Access 2018, 6, 28417-28437. [CrossRef]

109. Pournader, M.; Shi, Y.; Seuring, S.; Koh, S.L. Blockchain applications in supply chains, transport and logistics: A systematic review of the literature. Int. J. Prod. Res. 2020, 58, 2063-2081. [CrossRef]

110. ElMaraghy, H.A. Flexible and reconfigurable manufacturing systems paradigms. Int. J. Flex. Manuf. Syst. 2005, 17, 261-276. [CrossRef]

111. Fasth-Berglund, Å.; Stahre, J. Cognitive automation strategy for reconfigurable and sustainable assembly systems. Assem. Autom. 2013, 294-303. [CrossRef]

112. Stock, T.; Seliger, G. Opportunities of sustainable manufacturing in industry 4.0. Procedia CIRP 2016, 40, 536-541. [CrossRef]

113. Pfeiffer, S. Robots, Industry 4.0 and humans, or why assembly work is more than routine work. Societies 2016, 6, 16. [CrossRef]

114. Frey, C.B.; Osborne, M.A. The future of employment: How susceptible are jobs to computerisation? Technol. Forecast. Soc. Chang. 2017, 114, 254-280. [CrossRef]

115. Gualtieri, L.; Rojas, R.; Carabin, G.; Palomba, I.; Rauch, E.; Vidoni, R.; Matt, D.T. Advanced Automation for Smes in The I4.0 Revolution: Engineering Education and Employees Training in The Smart Mini Factory Laboratory. In Proceedings of the IEEE International Conference on Industrial Engineering and Engineering Management (IEEM), Bangkok, Thailand, 16-19 December 2018; pp. 1111-1115.

116. Agostini, L.; Nosella, A. The adoption of Industry 4.0 technologies in SMEs: Results of an international study. Manag. Decis. 2019, 625-643. [CrossRef]

117. Tan, K.H.; Ji, G.; Lim, C.P.; Tseng, M.-L. Using big data to make better decisions in the digital economy. Int. J. Prod. Res. 2017, 55, 4998-5000. [CrossRef]

118. Klünder, T.; Dörseln, J.N.; Steven, M. Procurement 4.0: How the digital disruption supports cost-reduction in Procurement. Production 2019, 29. [CrossRef]

119. Bontoux, L.; Bengtsson, D. 2035-Paths Towards a Sustainable EU Economy: Sustainable Transitions and the Potential of Eco-Innovation for Jobs and Economic Development in the EU Eco-Industries 2035. Available online: https://publications.jrc.ec.europa.eu/repository/bitstream/JRC96826/kjna27376enn.pdf (accessed on 10 September 2020). 
120. Dubey, R.; Gunasekaran, A.; Papadopoulos, T.; Childe, S.J.; Shibin, K.T.; Wamba, S.F. Sustainable supply chain management: Framework and further research directions. J. Clean. Prod. 2017, 142, 1119-1130. [CrossRef]

121. Magruk, A. Uncertainty in the sphere of the industry 4.0-potential areas to research. Bus. Manag. Educ. 2016, 14, 275-291. [CrossRef]

122. Zheng, T.; Ardolino, M.; Bacchetti, A.; Perona, M.; Zanardini, M. The impacts of Industry 4.0: A descriptive survey in the Italian manufacturing sector. J. Manuf. Technol. Manag. 2019. [CrossRef]

123. Grzybowska, K.; Łupicka, A. Key competencies for Industry 4.0. Econ. Manag. Innov. 2017, 1, $250-253$.

124. Tsai, W.-H.; Lai, S.-Y. Green production planning and control model with ABC under industry 4.0 for the paper industry. Sustainability 2018, 10, 2932. [CrossRef]

125. Micieta, B.; Binasova, V.; Lieskovsky, R.; Krajcovic, M.; Dulina, L. Product segmentation and sustainability in customized assembly with respect to the basic elements of industry 4.0. Sustainability 2019, 11, 6057. [CrossRef]

126. Greenbaum, T.L. The Handbook for Focus Group Research, 2nd ed.; Sage Publications: Thousand Oaks, CA, USA, 1998; pp. 1-33.

127. Edmunds, $\mathrm{H}$. The focus group research handbook. Bottom Line 1999, 12, 46. [CrossRef]

128. Chioncel, N.E.; van der Veen, R.G.W.; Wildemeersch, D.; Jarvis, P. The validity and reliability of focus groups as a research method in adult education. Int. J. Lifelong Educ. 2003, 22, 495-517. [CrossRef]

129. Miragliotta, G.; Shrouf, F. Using Internet of Things to Improve Eco-Efficiency in Manufacturing: A Review on Available Knowledge and a Framework for Iot Adoption. In Proceedings of the IFIP International Conference on Advances in Production Management Systems, Rhodes, Greece, 24-26 September 2012; Emmanouilidis, C., Taisch, M., Kiritsis, D., Eds.; Springer: Berlin/Heidelberg, Germany, 2012; pp. 96-102. [CrossRef]

130. Porter, M.E. Competitive Advantage of Nations: Creating and Sustaining Superior Performance; The Free Press: New York, NY, USA, 2011; pp. 33-69.

131. Ramsauer, C. Industrie 4.0-Die Produktion der Zukunft. WINGbusiness 2013, 3, 6-12.

132. Felsberger, A.; Reiner, G. How to Measure the Impact of Digital Transformation Along Industrial Value Chains? Cases of the Semiconductor Industry. In Proceedings of the 25th European Operations Management Association Conference (EurOMA), Budapest, Hungary, 24-26 June 2018; pp. 1-10.

133. Carter, C.R.; Rogers, D.S. A framework of sustainable supply chain management: Moving toward new theory. Int. J. Phys. Distrib. Logist. Manag. 2008, 38, 360-387. [CrossRef]

134. Holliday, C.O.; Schmidheiny, S.; Watts, P. Walking the Talk: The Business Case for Sustainable Development; Berrett-Koehler Publishers: San Francisco, CA, USA, 2002; pp. 11-37.

135. Gimenez, C.; Sierra, V.; Rodon, J. Sustainable operations: Their impact on the triple bottom line. Int. J. Prod. Econ. 2012, 140, 149-159. [CrossRef]

136. Remes, J.; Mischke, J.; Krishnan, M. Solving the productivity puzzle: The role of demand and the promise of digitization. Int. Product. Monit. 2018, 35, 28-51.

137. Felsberger, A. Automatisierung und Digitalisierung: Smart Factory. In Digitalisierung: Intersdisziplinäre Perspektiven auf Wirtschaftlichen, Politischen und Kulturellen Wandel; Groß, H.P., Reiner, G., Eds.; Profil Verlag GmbH: Wien, Austria, 2020.

138. Agarwal, N.; Brem, A. Strategic business transformation through technology convergence: Implications from General Electric's industrial internet initiative. Int. J. Technol. Manag. 2015, 67, 196-214. [CrossRef]

139. Schneider, P. Managerial challenges of Industry 4.0: An empirically backed research agenda for a nascent field. Rev. Manag. Sci. 2018, 12, 803-848. [CrossRef]

140. European Commission-Cordis EU Research Results. Flexible and Autonomous Manufacturing Systems for Custom-Designed Products: (FASTEN). Available online: https://cordis.europa.eu/project/id/777096 (accessed on 11 September 2020).

141. European Commission-Cordis EU Research Results. A COmprehensive Cyber-Intelligence Framework for Resilient coLLABorative Manufacturing Systems: (COLLABS). Available online: https://cordis.europa.eu/ project/id/871518 (accessed on 11 September 2020).

142. Thames, L.; Schaefer, D. Software-defined cloud manufacturing for industry 4.0. Procedia Cirp 2016, 52, 12-17. [CrossRef] 
143. Fettermann, D.C.; Cavalcante, C.G.S.; de Almeida, T.D.; Tortorella, G.L. How does Industry 4.0 contribute to operations management? J. Ind. Prod. Eng. 2018, 35, 255-268. [CrossRef]

144. Dalenogare, L.S.; Benitez, G.B.; Ayala, N.F.; Frank, A.G. The expected contribution of Industry 4.0 technologies for industrial performance. Int. J. Prod. Econ. 2018, 204, 383-394. [CrossRef]

145. Barton, R.; Thomas, A. Implementation of intelligent systems, enabling integration of SMEs to high-value supply chain networks. Eng. Appl. Artif. Intell. 2009, 22, 929-938. [CrossRef]

(C) 2020 by the authors. Licensee MDPI, Basel, Switzerland. This article is an open access article distributed under the terms and conditions of the Creative Commons Attribution (CC BY) license (http://creativecommons.org/licenses/by/4.0/). 